\title{
¿FANTASÍA O REALIDAD? LA VIHUELA EN LAS OBRAS DE CABEZÓN
}

\section{FANTASY OR REALITY? THE VIHUELA IN THE OBRAS OF CABEZÓN}

\author{
John Griffiths \\ Monash University y University of Melbourne
}

\begin{abstract}
Resumen
En este artículo se examina el lugar de la vihuela en las Obras para tecla arpa y vihuela de Cabezón. En primer lugar se examina el tema en términos estilísticos, la adaptabilidad de la notación de Cabezón, y el alcance de las modificaciones necesarias para lograr una adaptación satisfactoria para un instrumento de cuerda pulsada. En segundo lugar, se examinan las circunstancias que rodean la publicación de las Obras y la influencia del Libro de cifra nиеva de Venegas de Henestrosa en determinar su notación, diseño y contenidos. El estudio muestra que sólo una pequeña proporción de la música de Cabezón es fácilmente transferible a la vihuela, y que la evidencia tiende hacia la conclusión de que la vihuela no forma parte del pensamiento de su autor, sino que la inclusión de la vihuela fue apropiado del libro de Venegas, quizás con la idea de ampliar la circulación de un libro que tendría una clientela bastante restringida.
\end{abstract}

\footnotetext{
Palabras clave

Vihuela, tecla, órgano, arpa, cifra musical, Cabezón, Venegas de Henestrosa, imprenta musical
}

Nuevas formas de notación para música instrumental figuran entre las principales innovaciones musicales del siglo XVI. Eran sistemas generalmente numéricos o alfabéticos de lectura fácil, igualmente accesibles para eruditas o ignorantes, y permitían escribir polifonía en partitura de una forma lógica y eficiente. Salvo unas notables excepciones medievales, la polifonía se copiaba, se interpretaba y se conservaba en voces individuales distribuidas en diferentes partes de la misma página si no en librillos individuales para cada voz. De esta forma de presentar la música surgen muchas preguntas en cuanto a su proceso de composición, su

\begin{abstract}
This article examines the place of the vihuela within Cabezón's Obras para tecla, arpa y vihuela. It examines the issue, firstly, in terms of musical style, the adaptability of Cabezón's notation, and the extent of the modifications needed to adapt the music satisfactorily for a plucked instrument. Secondly, it examines the circumstances surrounding the publication of the Obras and the influence on its notation, style and contents that were derived from de Libro de cifra nueva of Venegas de Henestrosa. The study demonstrates that only a small proportion of Cabezón's music is easily transferable to the vihuela, and the evidence tends towards the conclusion that the vihuela was of little interest to the keyboard composer, but that the inclusion of the vihuela in the title was appropriated from Venegas, perhaps with a mind to increasing the circulation of a book which otherwise would only have a restricted clientele.
\end{abstract}

\section{Keywords}

Vihuela, keyboard, organ, harp, tablature, Cabezón, Venegas de Henestrosa, music printing

aprendizaje, su comprensión y su transmisión ${ }^{1}$. Hasta cierto punto, investigadores recientes han podido aclarar algunos de los métodos empleados por los músicos para superar los obstáculos que resultaban de esas prácticas de notación. Dejando por un lado la incógnita del papel de la memoria en la composición e interpretación musical en los siglos XV y XVI, las investigaciones de Jessie Ann Owens entre otros

1 Entre las más notables se incluyen las obras polifónicas del Codex Calixtinus del siglo XII y el organum conservado en los manuscritos de Wolfenbüttel (D-W MSS 677 y 1026) y Florencia (I-Fl Pluteus 29.1) que supuestamente constituyen el supuesto Magnus liber organi de la catedral de Notre Dame de Paris. 
han descubierto varios de los soportes efímeros empleados en el proceso compositivo como planchas de cera, pizarras o fragmentos de papel usado, junto con el empleo de las nuevas notaciones instrumentales ${ }^{2}$. Con números o letras para reemplazar a las figuras habituales de la notación mensural, las notaciones instrumentales efectivamente reducían la música a un tipo de tabla o trazado cuadricular que los italianos llamaban intavolatura, término adoptado y traducido por músicos de otras nacionalidades excepto en España donde se entendía simplemente como "música en cifra" o "cifras". Las intavolature para instrumentos de tecla y cuerda pulsada consiguieron una rápida aceptación e importancia que fue más allá de los confines de la práctica instrumental en sí, ya que ofrecían a sus creadores - quienes también solían ser instrumentistas - una partitura para el que quisiera estudiarlo o interpretarlo. El éxito de estas intavolature también puede haber contribuido a la pervivencia a lo largo del siglo XVI de la práctica continuada de escribir la polifonía en voces individuales, incluso después de que se hubieran desarrollado las tecnologías necesarias en la imprenta musical para favorecer la producción de partituras.

La notación cifrada para instrumentos de tecla parece ser un invento alemán que fue adoptado posteriormente en España. En Italia y Francia, en cambio, los organistas y clavecinistas empleaban varios tipos de partituras, a veces con más de una voz por pentagrama o en pautas múltiples. Las primeras Tablaturen alemanas, como la Fundamenta organisandi (1451) de Conrad Paumann o el Buxheimer Orgelbuch (c.1470), combinaban lo nuevo con lo antiguo, empleando notación convencional mensural para la mano derecha con un nuevo sistema para la izquierda que utilizaba las letras del abecedario. Es probable que el origen de esta notación fue una forma abreviada de escribir la música para la mano izquierda junto con una melodía ya existente, ocupando el espacio debajo del pentagrama donde normalmente se escribía la letra y utilizando los nombres alfabéticos de las notas desde la $A$ a la $G$ con valores rítmicos anotados encima de las letras. Con este sistema se escribían obras polifónicas hasta cuatro voces, cada voz de la Tablatur en una línea independiente. A mediados del siglo XVI, los organistas alemanes ya habían dejado de escribir la voz superior en notación mensural, escribiendo todas las voces en letras, y creando así una práctica que seguiría vigente hasta bien entrado el siglo XVIII.

No hay evidencia segura para afirmar con certeza que los organistas españoles conocían la intavolatura alemana. Sin embargo, y sin saber ni la ruta ni las circunstancias, es

2 OWENS, 1997. probable que esta notación alemana se conociera en la Península Ibérica e influyera en el desarrollo de sistemas autóctonos. Esta es la explicación más plausible de por qué la notación de la fuente ibérica de cifra para órgano más antigua que se conoce, el Arte de tanger (Lisboa, 1540) de Gonzalo de Baena, se basa en letras en vez de números ${ }^{3}$. Igual que los alemanes, Baena indica los nombres de las notas con letras de la $A$ a la $G$, y mantiene las voces en filas una encima de la otra, y todo ello dentro de un novedoso trazado cuadricular de su propia invención que mide y marca el compás. Juan Bermudo aclara en su Declaración de instrumentos musicales en 1555 que en España se conocían varios sistemas de cifras para instrumentos de tecla y que no existía ninguna uniformidad. El teórico ejemplifica su argumento con dos formas diferentes de cifras para tecla, y también reconoce la existencia de varios sistemas basados en letras ${ }^{4}$. En décadas posteriores en España, los sistemas numéricos sustituyeron a los alfabéticos, pero no hay evidencia clara de que ningún sistema particular llegara a ser dominante. De hecho, los dos libros en cifras editados en España y sus territorios a finales de los años setenta, Obras de música (Madrid, 1578) de Hernando de Cabezón, que es el objeto principal de este estudio, e Intavolatura de Cimbalo (Nápoles, 1576) de Antonio Valente, emplean sistemas diferentes de notación y comprueban la falta de un sistema uniforme.

Con una sola excepción, los libros españoles para vihuela muestran una notable uniformidad en su notación, un sistema de cifras derivado del italiano en lugar de los sistemas desarrollados en otras partes de Europa. La cifra española para vihuela, conforme con la intavolatura italiana, se basa en un sistema numérico que intenta ser una representación gráfica del lugar donde se colocan los dedos en el diapasón del instrumento; las cifras indican los trastes y van superpuestos encima de un hexagrama que representa las cuerdas, con el tiempo entre pulsaciones - el ritmoindicado por figuras rítmicas colocadas encima. El sistema hispano-italiano no es muy diferente del francés que sustituye las cifras por letras alfabéticas e invierte el hexagrama para señalar la chanterelle en la raya superior. El alemán, en cambio, parece derivarse del sistema para instrumentos de tecla y es el único que no pretende dibujar el diapasón del laúd, sino indicar con una letra o cifra cada intersección de cuerda y traste en el instrumento. El primer libro español en cifras para vihuela, El maestro (1536) de Luis Milán es parecido al Arte de tanger de Gonzalo de Baena en emplear una notación única que representa las cuerdas de forma in-

3 El único ejemplar de BAENA, 1540 se conserva en la Biblioteca del Palacio Real de Madrid, signatura VIII/1816.

4 KNIGHTON, 1996: 83-85. 
vertida ${ }^{5}$. Con esta única excepción, todos los demás libros de españoles de cifra se conforman en casi todos sus detalles con la variedad de intavolatura italiana que se emplea por primera vez en la Intabolatura de leuto que edita Giovanni Antonio Casteliono en Milán en 1536, sobre todo por el uso de las figuras normales mensurales para indicar el ritmo en vez de los signos especiales - solamente plicas y corchetes sin cabeza - que eran la norma en Italia, apareciendo por primera vez en los libros editados en Venecia por Petrucci a partir de 1507 y manteniéndose en vigor hasta 1600 aproximadamente ${ }^{6}$. Este primer libro editado por Casteliono es probablemente el modelo que sirvió a Luis de Narváez y a su impresor Diego Fernández de Córdoba para diseñar Los seys libros del Delphín en 1538, desde su aspecto general hasta las cifras y signos rítmicos e incluso la técnica de impresiones múltiples empleada en su producción ${ }^{7}$.

El motivo de comenzar este estudio con reflexiones sobre la historia y el desarrollo de las cifras para tecla y vihuela es el de establecer el contexto de las Obras de música para tecla, arpa y vihuela de Antonio de Cabezón editado por su hijo Hernando en 1578. En muchos sentidos fue una publicación que iba en contra de la corriente de la época. Dejando por un lado las cuestiones estilísticas, fue una obra editada en un momento en el que la notación de música instrumental iba haciéndose más idiomática y se iba refinando para adecuarse a las necesidades de los distintos instrumentos de su tiempo. Sin embargo, Hernando de Cabezón, claramente inspirado en otras publicaciones anteriores, decide sacar un libro con una sola notación que serviría para tres instrumentos diferentes ${ }^{8}$. Tercer y último de los libros compuestos con la misma intención, da la impresión de ser un libro con un repertorio de música universal e intercambiable que se podía tocar en los tres instrumentos indicados.

El propósito, pues, del presente estudio es el de explorar hasta qué punto el gran organista concebía realmente su música de esta manera o si el título del libro fue un invento de Hernando basado en motivos comerciales en vez de rendir homenaje a su padre difunto. Este estudio supone, naturalmente, explorar las relaciones entre la trilogía el Libro de cifra nueva (1557) de Luis Venegas de Henestrosa, el Arte de tañer fantasía (1565) de Tomás de Santa María, y las Obras de música de los Cabezón'. Hay que establecer por qué estos autores

5 El las cifras de Milán, la línea superior del hexagrama representa la prima en vez de la sexta cuerda, similar a la intavolatura napolitana.

6 El primer libro de emplear el sistema de notas descabezadas es SPINACINO, 1507.

7 GRIFFITHS, 2010: 14

8 CABEZÓN, 1578.

9 VENEGAS DE HENESTROSA, 1557, con edición moderna en ANGLÉS, 1944, y SANTA MARÍA, 1565 y la edición moderna de 2007. querían que su música fuera "para tecla, arpa y vihuela": si era una novedad, si ya existía una práctica escondida de intercambio instrumental, o si por el contrario era una innovación comercial motivada por un deseo de aumentar el consumo de sus productos en un mercado más amplio. Debemos por tanto examinar evidencias tanto internas como externas ya que la cuestión es tanto histórica como estilística. Debemos también establecer las similitudes y diferencias interpretativas entre cada uno de los instrumentos en cuestión y establecer, desde un punto de vista musical, lo que suponía adaptar la música de Cabezón a la vihuela o al arpa. Hay que analizar también si las diferencias entre distintos sistemas de notación imponían barreras que restringían el libre intercambio musical entre tañedores de diferentes instrumentos; si a los vihuelistas y arpistas les interesaba el repertorio de los autores de estos libros, o si tenían la competencia musical para adaptar la música a sus necesidades, bien sobre el libro o por escrito.

\section{LA VIHUELA EN EL PRÓLOGO DE LAS OBRAS DE MÚSICA}

Para cualquiera que se interese por la vihuela, es difícil leer los extensos textos preliminares de la Obras de música sin notar la ausencia casi completa de este instrumento, tanto en el "Proemio" laudatorio como en la "Declaración de la cifra". Es difícil interpretar esta ausencia como otra cosa que una falta de interés, entusiasmo o conocimiento por parte de Hernando de Cabezón. La evidencia está bastante clara. Lo que pretendemos mostrar aquí es que el libro que publicó en 1578 representa una colección de piezas para órgano de su padre, el Compendio de música, pero la adición del arpa y la vihuela tanto como el cambio de su nombre a Obras de música fueron decisiones tomadas mucho después de su creación inicial, esta última casi al terminar la impresión. La inclusión de los instrumentos no de tecla está señalada ya en septiembre de 1575 cuando Cabezón suplica licencia del rey para su edición. Es imposible afirmar que haya sido por iniciativa del padre o del hijo, pero a nuestro juicio la totalidad de la evidencia se inclina hacia Hernando, a pesar de las palabras de Felipe II que nos harían creer que fuera la intención de su padre ya que en la petición de Hernando podemos leer:

nos fue fecha relación diziendo que Antonio de Cabeçón vuestro padre, músico que ansí mismo fue de nuestra cámara y capilla auía hecho y ordenado, vn libro intitulado Compendio de música: el qual seruía para tecla, vihuela y arpa, y vos le auíades recopilado y puesto en cifra... ${ }^{10}$

10 CABEZÓN, 1578: fol. iiv. ANGLÉS, 1944: 13-14. 
El pasaje citado también nos haría creer que Compendio de música fuese el título que Antonio de Cabezón pensaba utilizar para la eventual publicación de sus obras, aunque tampoco podemos afirmarlo con seguridad por los mismos motivos. Lo único seguro es que ya en 1575 era el título que Hernando había decidido utilizar, y que seguía siendo su intención hasta casi el último momento. La comprobación de este detalle es simplemente el hecho de que los 201 folios de música del libro están todos encabezados con el título Compendio de música mientras que el de Obras de música solamente figura en la portada que, con toda probabilidad, fue lo último que se imprimió. Era habitual en la producción de libros para que pudieran, después de terminar la impresión del cuerpo principal, volver al principio e imprimir los índices y tablas que precisaban paginación exacta, más una fe de erratas. En este caso particular, también se incluye la certificación del Consejo Real que indica que la impresión se había hecho conforme con el manuscrito original y la tasación del libro en un ducado y medio. Confirma que los folios preliminares no se imprimieron en el mismo momento que el cuerpo principal, sino un tiempo después, conforme con lo que se observa en la paginación de imprenta dentro del libro. Los veinticinco cuadernos que corresponden al cuerpo principal están numerados de la $\mathrm{A}$ a la $\mathrm{Z}$, seguido por $\mathrm{Aa}$ y $\mathrm{Bb}^{11}$. En cambio, los folios introductorios forman dos cuadernos de seis folios, el primero numerado con asteriscos $(* 1, * 2$, etc.) y el segundo numerado con el símbolo en vez de una letra ${ }^{12}$. De esto se deduce que fue durante este periodo que Hernando de Cabezón decidió cambiar su título original de Compendio de música a Obras de música para tecla, arpa y vihuela.

Hay dos detalles más en la introducción de las Obras de música que también infieren que las piezas en las Obras de música no fueran concebidas originalmente "para tecla, arpa y vihuela". El primero es el comentario de Hernando de Cabezón en el que declara de "auer querido juntar en este libro algunas cosas que él [su padre] dio de lición a sus discípulos", los cuales suponemos no haber sido arpistas ni vihuelistas ${ }^{13}$. En este caso, la decisión de ampliar el horizonte del libro debía corresponder a otro motivo, posiblemente comercial. El segundo detalle es el pasaje de la licencia citado arriba en el que Hernando declara que fue él quien había "puesto en cifra" la música de su padre. Una de las posibles

11 Todos menos cinco cuadernos son regulares: cuaderno B es de cuatro folios, cuaderno $\mathrm{V}$ es de seis, $\mathrm{y}$ hay cuatro $(\mathrm{M}, \mathrm{N}, \mathrm{Z}$ y $\mathrm{Bb}$ ) que son cuadernillos de diez folios.

12 Los folios del segundo cuaderno preliminar están encuadernados incorrectamente en el ejemplar en la Biblioteca Nacional de Madrid. En su estado actual, fol. 2-2v es el último folio del cuaderno.

13 CABEZÓN, 1578, Advertencias: fol. [ 6r]. interpretaciones de esta frase es que Antonio, debido a su ceguera, hubiese empleado a un amanuense para ayudarle escribir las piezas, pero en una notación desconocida y diferente a la cifra del libro editado, quizás en partitura como encontramos en los conocidos manuscritos conservados en Coimbra ${ }^{14}$. Una segunda posibilidad es que la tarea de amanuense le correspondiera desde joven a Hernando en capacidad de hijo aprendiz y quizás también lazarillo de su padre, y que él mismo pusiese la música de su padre en cifra en el acto para los alumnos. La otra opción es que Antonio enseñara a sus alumnos sin partitura alguna y que Hernando, en una fecha posterior, pusiese en cifra lo que había retenido en su memoria de las lecciones que su padre daba a sus alumnos. En cualquiera de estas circunstancias, estamos lejos de un posible uso de esta música por tañedores de arpa o vihuela antes de su publicación.

En el Proemio laudatorio de las Obras de música, Hernando de Cabezón alude específicamente a la vihuela únicamente en tres momentos aparte de aquellos pasajes que invocan a las liras y cítaras y otros instrumentos de cuerda pulsada en manos de dioses y personajes mitológicos de la Antigüedad. La vihuela aparece por primera vez en la parte del Proemio que Cabezón dedica a la función terapéutica de la música y su capacidad de armonizar el cuerpo con el ánima, tratando al instrumento de forma alegórica para ejemplificar cómo el ser humano debe aspirar a su propia templanza:

pues los humores del cuerpo son salud y destemplados causan enfermedad y muerte, como lo consideran los Músicos desta parte que son los Médicos, los quales tocando los trastes desta vihuela conocen en el pulso quando no está templada, y procuran con su arte reduzirla en su primer concierto, y tanto es esto assí, que la misma ánima del hombre dixo Aristóxeno Músico y Philósopho insigne, no e[s] otra cosa sino aquella armonía que del concierto del cuerpo y sus partes resultaua... ${ }^{15}$

Los demás pasajes que aluden a la vihuela son citas que se refieren a la vihuela en refranes populares de la época. No son referencias de tono innecesariamente negativo, pero tampoco son frases que contribuyan a la mitificación del instrumento. En la primera cita, Cabezón invoca un dicho común de la época, transmitido desde la Antigüedad por Boecio, en el que el asno y la vihuela son los polos opuestos de sensibilidad artística:

14 P-Cug, MSS 48 y 242 (Biblioteca Geral da Universidade, Coimbra). Véase KASTNER, 1950 y DODERER, 2011.

15 CABEZÓN, 1578: fol. *3. Hemos corregido el texto, reemplazando la palabra "en" con "e[s]". 
Y si todavía queda alguno que no guste de la música, bien será que sepa el nombre que tiene en el proverbio latino, en el qual, queriendo notar a uno por incapaz de entender cosa de ingenio, le llamamos asno a la vihuela, como si dixésemos que aun de los animales brutos ninguno ay, sino éste, que de la música no guste. ${ }^{16}$

Sin duda, la intención no es de menospreciar a la vihuela, igual que en la cita siguiente en la que Hernando recurre a otro dicho que le permite concluir sus alabanzas a la música civilizadora de la Antigüedad. Después de reclamar que su propósito no era "de hazer libro, en lugar de prefación", argumenta que "entre otras excelencias, tiene también la Música el ser enemiga de parleros, y poner silencio donde entra, lo qual significan los latinos en un proverbio que dize: ¿qué tiene que ver el grajo con la vihuela?"17

Estas referencias se encuentran en el contexto de un Proemio que alaba abiertamente al órgano, no solo por su significado religioso como instrumento principal que habita en la "casa del Señor", sino también por sus cualidades musicales y espirituales. Sus alabanzas del órgano asumen un tono casi místico de Cabezón, un instrumento que "como el buen niño Samuel, amado de Dios, no sale del templo días ni noches, paresciéndose en esto a los religiosos que gozan de aquella bendición que el Espíritu Sancto da por David a los que residen siempre en la casa de Dios ocupados en alabarle"18. Esta predilección por el órgano va más allá que una simple preferencia por los instrumentos de tecla frente a los de cuerda pulsada. Cabezón también señala la superioridad del órgano comparado con los demás instrumentos de tecla los cuales, según él, solo sirven como herramientas didácticas para aprender el órgano, un instrumento aparentemente demasiado noble para relegar a tareas didácticas, debido a:

.. la magestad y señorío deste instrumento en el apparato y servicio que solo él tiene entre todos los demás, y no consentir ser tocado de manos rudas y principiantes, ni exerticarse en él la gramática de enseñar, ni la molestia del deprender y estudia, teniendo otros instrumentos menores a que $\mathrm{n}$ tiene cometido esto, que son los que llaman monacordio y clavicordio. ${ }^{19}$

Numerosas alusiones a instrumentos de cuerda pulsada en los poemas dedicatorios que siguen el Proemio repiten

16 CABEZÓN, 1578: fol [*5r], "Proemio". Véase DOÑAS, 2010: 20-23.

17 ibid.

18 CABEZÓN, 1578 , fol. *5v.

19 ibid. las habituales referencias humanistas a las grandes figuras de la Antigüedad y a las leyendas de Orfeo, Arion y Anfión en las que abundan la lyra y la cithara, empleadas para crear analogías con el efecto creado por Antonio de Cabezón y su música. Todos ellos figuran juntos y unidos en los primeros cuartetos de un soneto de la pluma de Alonso de Morales Salado que alaba al gran organista ${ }^{20}$ :

Si Orpheo con su dulce y triste canto,pudo mover las furias infernales:si Arión cantando sus terribles males,cobró la vida con su proprio llanto.

Y si con lyra pudo Anphión tanto,Que edifico de Thebas muros tales:¿Quién ha excedido a todos los mortales,A quien no causara mayor espanto $?^{21}$

Referencias a la vihuela en la "Declaración de la cifra que en este libro va" son igualmente escasas como en el "Proemio". Al principio de este texto preliminar, $\mathrm{Ca}$ bezón declara de forma ecuménica que todos los usuarios del libro necesitan tener unos conocimientos básicos, que "el que quisiera poner las obras de él en Tecla, Harpa o Vihuela, ha de saber cantar y tener muy conocidos en la memoria, los signos de la Música," es decir, de la notación mensural $^{22}$. La vihuela se menciona en dos momentos más. El primero es en la explicación de la notación de las notas cromáticas en la cifra: "Los bemoles que ordinariamente caen en el quatro y en el siete... en el órgano se ha de herir la tecla más abaxo... y en la Harpa y Vihuela en los trastes o cuerdas donde los Bemoles se causarem [sic]." ${ }^{23}$ La falta de una explicación igualmente explícita para los arpistas y vihuelistas no significa necesariamente un desconocimiento del funcionamiento de estos instrumentos; más bien podría leerse como un añadido superficial, o simplemente un reconocimiento que las notas cromáticas son igualmente posibles en el arpa y la vihuela como en los instrumentos de tecla.

Hacia finales de su explicación de la cifra, Hernando de Cabezón ofrece un consejo más a los vihuelistas que pretenden tocar del libro en el cual reconoce que será necesario simplificar la música y omitir voces en determinadas situaciones:

20 Un poeta poco conocido alabado por Cervantes en la canción de Calliope en La Galatea, libro 6, según informa MANCING 2004: vol. 2, 494. Otro soneto laudatorio "Edad felice, siglo venturoso" del mismo autor se encuentra en OVIEDO, 1581, citado en SIMÓN DÍAZ 1950-1993: vol. 16 (1993), 360.

21 CABEZÓN, 1578: fol. *7v

22 CABEZÓN, 1578: fol. *9v

23 Ibid. 
Los que quisieren aprovechar deste libro en la vihuela, tengan quenta que toparan algunas vezes dos vozes que van glosando, han de dexar la vna, que menos al caso les paresciere hazer, y ansi se podrán tañer con facilidad todo lo que en este libro va cifrado, y más los que acostumbran tañer en vihuela de siete órdenes.

Su comentario final sobre la ventaja que tiene la vihuela de siete órdenes simplemente se debe a que la adición del séptimo orden amplía el ámbito del instrumento hasta tres octavas y aumenta las posibilidades de tocar la música de Cabezón en ella, aunque no resuelva la necesidad de suprimir la glosas simultáneas en dos voces.

\section{CABEZÓN EN LA VIHUELA}

Si hasta aquí nuestro estudio se ha enfocado en la cuestión de la concepción de la música de Antonio de Cabezón y las intenciones tanto de él como de su hijo, el hecho es que las Obras de música se publicaron explícitamente con el título inequívoco "para tecla, arpa y vihuela". Ahora nos corresponde investigar las cuestiones prácticas, sobre lo posible y lo imposible, lo fácil y lo difícil, y el resultado de interpretar la música de las Obras de música en la vihuela en términos técnicos, estéticos y musicales. Nuestras observaciones influirán en la evaluación de las cuestiones que rodean la supuesta práctica de intercambio musical entre arpa, vihuela y los instrumentos de tecla, y el concepto de un repertorio común y universal que se deriva de los títulos de los libros como las Obras de música de Cabezón. Esto supone comparar no solamente las diferencias físicas y mecánicas entre los diferentes instrumentos y las respectivas limitaciones musicales que circunscriben su técnica instrumental, sino también su notación y la mecánica de trasladar la música de un instrumento a otro a través del sistema de notación que emplea Cabezón. El presente estudio brinda la oportunidad de investigar este aspecto con cierta profundidad y reafirmar que solamente un número reducido de las piezas en las Obras de música se adaptan técnicamente y estéticamente a la vihuela.

La música polifónica con texturas de hasta cuatro voces funciona con comodidad en la vihuela, principalmente en obras imitativas o en las que se basan en una voz principal acompañada por acordes. Las texturas de tres voces son excelentes y permiten una gran claridad polifónica en su interpretación. Las obras a cuatro voces con textura más abierta, es decir, con periodos de silencio en una o más voces como abundan en la música de Josquin y Morales, se prestan especialmente, hecho reflejado en el alto número de obras de ambos compositores conservadas en el repertorio específica- mente para el instrumento. Por la densidad de sus texturas, las obras de cinco o más voces no se adaptan fácilmente, tanto por la dificultad técnica de mantener la individualidad de sus voces en un instrumento de seis o siete órdenes, como la imposibilidad de reproducir la individualidad tímbrica y espacial que caracteriza las voces de un conjunto vocal. No sobrevive ninguna composición original de ningún vihuelista para más de cuatro voces. Es solamente entre los arreglos de polifonía vocal para el instrumento donde se encuentra música a cinco, seis o más voces que, en su totalidad representan apenas el cuatro por ciento del repertorio total ${ }^{24}$. De forma parecida, las obras extremadamente glosadas presentan dificultades similares, simplemente porque al vihuelista le faltan dedos y cuerdas suficientes.

Otra dificultad en adaptar música para tecla a la vihuela es el hecho de que el ámbito de los instrumentos de tecla en el siglo XVI era aproximadamente una octava más grande que el de la vihuela. El ámbito de la vihuela era de dos octavas y una séptima, desde la sexta al aire hasta el décimo traste en la prima, aunque el ámbito más cómodo y manejable era más bien de dos octavas y una quinta, hasta el séptimo traste en la prima. Un porcentaje elevado de las obras de tecla son de tres octavas o más, lo cual representa uno de los problemas fundamentales en adaptar obras de un instrumento al otro. En general, son las obras de ámbito más estrecho que se prestan a la vihuela, a veces por razones relacionadas con su ámbito. Las modificaciones necesarias para reducir el ámbito de una obra para que quepa en la vihuela incluyen desde omitir notas no esenciales hasta transportarlas una octava. Se supone que los tañedores más hábiles habrían sido capaces de efectuar tales modificaciones en el acto, mientras otros habrían necesitado anotar los cambios en la cifra. Otros en cambio, sin los conocimientos o experiencia necesaria, habrían encontrado los obstáculos insuperables y el desafío más allá de sus límites.

Hasta cierto punto, las dificultades inherentes de ámbito y textura están moderadas por la densidad de las texturas, la velocidad de pasajes glosados, y la distribución de las notas en los acordes. La falta de obras glosadas - obras de polifonía vocal extremadamente ornamentadas del tipo que encontramos en las Obras de música de Cabezón - en el repertorio para vihuela, se atribuye simplemente a la dificultad de mantener una textura polifónica al mismo tiempo que glosar una de las voces. Piezas de este tipo funcionan

24 En los libros expresamente para vihuela, hay unas treinta y tres obras para cinco o más voces, excluyendo la música para dos vihuelas en VALDERRÁBANO, 1547. La mayoría son motetes y en algunas de estas piezas una de las voces está notada en un pentagrama aparte para ser cantada. 
mucho mejor en conjuntos de dos o tres instrumentos. No obstante, los dúos en Silva de sirenas de Valderrábano, los únicos ejemplos sobrevivientes de la época, tampoco llevan muchos pasajes glosados ${ }^{25}$.

La afinación de la vihuela en cuartas juega un papel determinante en las distancias cómodas entre los intervalos en los acordes y dificultan la adaptación literal de una obra concebida en un teclado. En el teclado, en cambio, el espacio entre las notas que corresponden a cada mano tienen que ser manejables, pero la distancia entre las manos puede permitir intervalos mayores en el medio de los acordes. Esta sutileza entre los dos instrumentos también es un factor que influye en la adaptación a las obras. Hay un cierto número de acordes en la música de Cabezón en los que es imposible mantener la misma distribución de notas en la vihuela. Ocurre principalmente cuando el intervalo entre el bajo y el tenor es de una tercera en vez de una quinta o una octava, o en acordes con un intervalo grande - una sexta o más - entre las voces tenor y contralto como ocurre, por ejemplo, en los acordes siguientes:

Acordes de este tipo son idiomáticos en los instrumentos de tecla pero no lo son en la vihuela. A veces son difíciles e incluso imposibles para la mano izquierda, o requieren a veces el uso del pulgar para pulsar simultáneamente las voces del bajo y tenor, con una pérdida de claridad polifónica como resultado.

Conforme con lo que advierte Hernando de Cabezón a los vihuelistas, hay algunas texturas que se tocan en los órganos y monacordios sin problema alguna y que resultan extraordinariamente difíciles en la vihuela. Entre las más complicadas de acomodar son los pasajes de movimiento rápido y simultáneo en dos o más voces. Los pasajes de sextas paralelas que emplea Cabezón con cierta frecuencia son frecuentemente difíciles de ejecutar en la vihuela, sobre todo si van en valores rápidos o si hay otra voz sonando a la $v^{2} z^{26}$. Las mismas dificultades se encuentran en otros pasajes de dos voces, como secuencias extendidas de décimas paralelas, movimiento contrario en semínimas of fusas, o pasajes extendidos de acordes en mínimas como el que crea el final del Tiento del segundo tono [no 62], compases $80-91^{27}$.

25 VALDERRÁBANO, 1547: fols. 45 a 63.

26 Por ejemplo, en la glosa sobre Prenez pitie (Crecquillon) en CABEZÓN, 1578: fol. 69, compases 78-79; edición moderna en CABEZÓN, 2010: vol. 3, 29, compases 78-79.

27 CABEZÓN, 1578: fol. 56v; CABEZÓN, 2010: vol. II, 150.

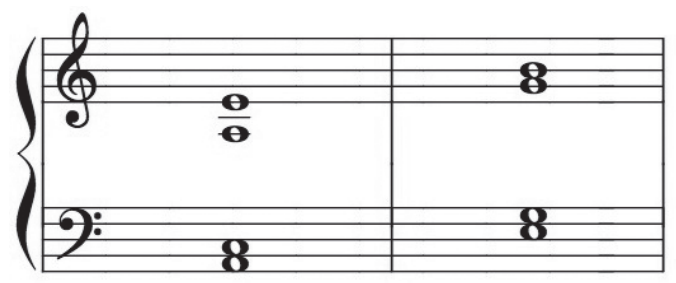

Otros elementos para tener en cuenta y que tienen relevancia en la adaptación de las obras de Cabezón para la vihuela, son más bien estéticos que técnicos, son sobre todos cuestiones generales relacionadas con determinadas texturas, la duración de las obras y la forma de su desarrollo. La música de vihuela es más bien un repertorio de miniaturas en el que las piezas que exceden a los cinco minutos son la excepción a la norma, todo lo contrario del órgano, por ejemplo. Esta realidad se debe a una diversidad de elementos que incluyen el volumen reducido de su sonido y la corta duración de sus notas que inhibe cualquier intento de tocar aquellas obras de Cabezón en las cuales su grandeza nace en los prolongados sonidos del órgano, los juegos imitativos, las ásperas disonancias con sus resoluciones, los cantus firmus sostenidos, y el tiempo en que se va desarrollando una obra. Son todos factores que el vihuelista tiene que tener en cuenta a la hora de escoger las obras que le van a servir en su instrumento.

\section{LA CIFRA DE CABEZÓN Y LA VIHUELA}

Independientemente de las diferencias idiomáticas entre los instrumentos de tecla y la vihuela, es el sistema semiótico en que se transmite la música de las Obras de música que tiene que ser un factor determinante en la adopción o rechazo por parte de los tañedores de vihuela de la música que contiene. La notación de Cabezón, basada en la cifra nueva inventada por Venegas de Henestrosa, y con pocas modificaciones, es un sistema que representa las notas por cifras que corresponden a las teclas del órgano $\mathrm{u}$ otro instrumento, y que se expresa gráficamente en un trazado cuadricular en el que las divisiones verticales son unidades temporales de un compás (tactus), y las horizontales indican la separación de las distintas "voces" de la textura polifónica. Las notas blancas del teclado están representadas por los números del 1 al 7, comenzando en $f a$. Las cifras correspondientes a cada octava se distinguen entre sí con lo que designa Venegas "rasguillos y puntillos". Las cifras de la octava aguda, la central, no llevan ninguna indicación; las de la octava grave, que es la inmediatamente inferior, 
llevan un "rasguillo" dibujado en cada una; las de la octave regrave (inferior a la grave) llevan rasguillos dobles, y por último en la octava sobreaguda las cifras están indicadas con puntillos en formas de apóstrofes después de cada cifra. Aplicado al teclado, este sistema es sumamente lógico ya que las teclas de cada octava forman un patrón visual repetido en cada octava superior o inferior. Las cifras funcionan de forma idéntica en cada octava y los rasguillos y puntillos solamente sirven para diferenciar entre octavas. Esta lógica se aplica igualmente al arpa con sus cuerdas de $f a$ y do teñidas, y las arpas dobles cuya invención es contemporánea a las Obras de música de Antonio de Cabezón. En cambio, no existe ninguna lógica física o visual entre la cifra de tecla y el diapasón de la vihuela. Obviamente, tiene que ser la falta de lógica intuitiva en la vihuela de este sistema de cifra que represente el obstáculo principal que se interpone entre la vihuela y la música de Cabezón. En su aspecto superficial la cifra para tecla y la de vihuela son bastante parecidas pero, en sus detalles, la correspondencia termina allí. Aunque lo fundamental es que cada sistema ofrezca al tañedor una instrucción física y mecánica para colocar los dedos, lo que representa cada uno son cosas completamente diferentes, basados en una lógica intuitiva que procede de cada instrumento. En la de tecla, las cifras representan las teclas, y las rayas horizontales separan las voces; en la de vihuela estas rayas son las cuerdas y las cifras son los trastes del diapasón donde se colocan los dedos. En la cifra de vihuela, por consiguiente, no hay una relación directa entre cifra y nota como es el caso de la cifra para tecla, no obstante, lo que tienen en común es que ambos sistemas indican una acción física: el instrumentista mueve los dedos a lugares determinados en el teclado o en el diapasón de la vihuela y ejecuta la acción física de apretar las teclas o pulsar las cuerdas indicadas. En ambos casos, esta acción fundamental no requiere ningún conocimiento musical, ni capacidad interpretativa. Más complejo sería el proceso mental si invirtiéramos la situación, requiriendo que el vihuelista tocara de la cifra para tecla y el organista tocara de la cifra de vihuela. Requiere una operación mental más: el organista tendría que memorizar las notas correspondientes a cada intersección de cuerda y traste en la vihuela, mentalmente convirtiendo cada cifra de vihuela en una nota antes de colocar su dedo sobre la tecla correspondiente. Este proceso obviamente requeriría bastante práctica antes de convertirse en un reflejo automático e instantáneo, y sería aun más complicado si tuviera que aprender hacerlo empleando las múltiples afinaciones imaginarias de la vihuela que proporcionan a cada intersección de cuerda y traste múltiples significaciones. La cifra 3 en la segunda cuerda, por ejemplo, sería un $f a$ en una "vihuela común" en sol (afinación: $\mathrm{sol}_{2}-\mathrm{do}_{3}-\mathrm{fa}_{3}-\mathrm{la}_{3}-\mathrm{re}_{4}-\mathrm{sol}_{4}$ ), un sol en una vihuela en $l a\left(l a_{2}-r e_{3}-s o l_{3}-s i_{3}-m i_{4}-l a_{4}\right)$, y un $d o$ en una vihuela en $\mathrm{re}\left(\mathrm{re}_{2}-\mathrm{Sol}_{2}-\mathrm{do}_{3}-\mathrm{mi}_{3}-\mathrm{la}_{3}-\mathrm{re}_{4}\right)$. No obstante, aprender a convertir las cifras de laúd y vihuela es uno de los desafíos que propone Venegas de Henestrosa a sus lectores en el prólogo de su Libro de cifra nueva, pero más bien con la intención no de hacerlo en el acto sino por escrito, como implica la rúbrica que encabeza el epígrafe, "Para passar la cifra antigua de la vihuela en ésta" 28 .

En la situación opuesta, la del vihuelista que quisiera tocar directamente de la cifra para tecla, el proceso posee dificultades similares debido a la falta de congruencia física entre cada cifra y su ubicación específica en el diapasón. Igual al organista en el caso anterior, el vihuelista que quisiera tocar directamente de la cifra de Cabezón tendría que memorizar los lugares correspondientes en el diapasón donde se encuentran. Al principio, por lo menos, esto significaría mentalmente convertir cada número de la cifra en la nota que correspondiera y entonces ubicarla en el diapasón: un proceso de múltiples pasos, de doble traducción. Con tiempo y repetición, este proceso se convierte hasta cierto punto en un reflejo automático, pero tres factores complican este proceso aun más: la complicación en la vihuela resultante de emplear las mismas cifras para cada octava, las múltiples ubicaciones de cada nota en el diapasón de la vihuela, y las múltiples aficiones imaginarias de la vihuela. Durante la fase de aprendizaje, por los menos, la lógica de la cifra de tecla es completamente ilógica en la vihuela. En el teclado, los números continúan subiendo por una escala ascendiente, y la repetición de las mismas cifras en cada octava es sumamente lógica: la secuencia numérica $5671^{\prime} 2^{2}$ claramente representa una escala ascendiente de do re mi fa sol, por ejemplo $^{29}$. En la vihuela, en cambio, la lógica de la repetición de las cifras desaparece y se convierte más bien en un obstáculo sicológico ya que la secuencia numérica, como la del ejemplo que citamos, va en contra de la numeración de los trastes que es siempre ascendiente. En situaciones menos fáciles, por ejemplo, en la siguiente secuencia de terceras descendientes encadenadas 3' 1'2' 71'675- (la-fa, sol$m i, f a-r e, m i-d o$ ), el desafío es mayor. El segundo factor que dificulta la lectura es uno de los mismos que existe también

28 VENEGAS DE HENESTROSA 1557: fols. 3v-4. "Para passar la cifra antigua de la vihuela en esta". No hay evidencia de ningún músico de la época que aprendió tocar directamente en un instrumento de tecla utilizando cifras de laúd o vihuela. De forma anecdótica y para indicar que no es una imposibilidad, hemos conocido personalmente a tres músicos que han aprendido tocar con facilidad de esta manera.

29 La existencia de otras versiones de cifra para tecla, como el sistema en VALENTE, 1576 que numera las teclas blancas de 1 a 27 y que a primera vista aparezca menos conveniente, puede atribuirse a una preferencia de no repetir las mismas cifras en cada octava. 
para leer la notación mensural en la vihuela, el hecho de que la mayoría de las notas se encuentran en la vihuela en múltiples lugares debido a su sistema de afinación. En una vihuela en $s o l$, por ejemplo, la $\mathrm{sol}_{4}$ de la prima el aire también se encuentra en la segunda en quinto traste y en la tercera en décimo traste. En este sentido, la cifra expresamente para vihuela elimina la necesidad de que el tañedor tenga que decidir las posiciones en el diapasón donde colocar los dedos. En obras complejas, estas cuestiones de digitación requieren cuidadosa atención, sobre todo si el tañedor realmente quiere incorporar todas las sutilezas contrapuntísticas de la música que intenta leer. Relacionado a este problema es la lectura de consonancias o acordes, el vocabulario de posturas comunes que concuerdan con las principales sonoridades verticales en la polifonía vocal y la música para tecla. Es de suponer que, con práctica, el vihuelista que decidiera tocar su instrumento a través de las cifras para tecla llegaría a reconocer estos conjuntos de notas y sus posturas correspondientes con la misma facilidad que desde la cifra para vihuela, aunque en un principio le costaría esfuerzo asimilarlo.

La tercera de las dificultades que identificamos para la lectura de la cifra de Cabezón en la vihuela, se debe al ámbito limitado del instrumento como hemos indicado anteriormente, y a la necesidad de transportar la música en algunas instancias para acomodarla en la vihuela. Estos transportes se efectuaban a través de las afinaciones imaginarias a que nos hemos referido ya. Se entiende que, durante el siglo XVI, en la gran mayoría de los casos el instrumento por defecto era la vihuela en sol, el que Juan Bermudo llama la vihuela común $^{30}$. Sin embargo, el teórico explica que frecuentemente era necesario imaginar que el instrumento fuese afinado en otro tono para acomodar obras vocales en él, invocando a los curiosos tañedores que "mudan el instrumento por la música" en vez de "muda[r] la música por el instrumento", explicando en detalle y con grabados los diapasones de vihuelas no solamente en sol y la, sino en $s i(\mathrm{Bmi}), d o, r e, m i$ y $f a^{31}$. En la música de Mudarra y Daza, también se encuentran obras para una vihuela en $f a$ sostenido, lo cual nos da un total de ocho afinaciones imaginarias. Utilizando estas afinaciones, el método para acomodar las obras para tecla en la vihuela es exactamente el mismo que se emplea para la polifonía vocal. Las explicaciones detalladas de Bermudo

30 BERMUDO, 1555: fol. 91. Aunque no lo especifique explícitamente, la afinación por defecto de Luis Milán era una vihuela en $l a$, hecho que se ve fácilmente comparando las cadencias finales de sus obras con las rúbricas al comienzo de cada una en que se especifica el tono en que va. Por otra parte, VENEGAS DE HENESTROSA 1557: fols. $3 \mathrm{v}-4$, indica una afinación en $m i$ en sus instrucciones.

31 BERMUDO, 1555: fol. 90v. indican que el primer factor es el ámbito de la obra. En primer lugar, hay que ver cuáles son los extremos de la pieza, y de ahí decidir dónde ubicar estas notas en el instrumento, en qué cuerda y en qué traste. En cuanto al extremo inferior, la práctica de los vihuelistas era la de ubicar esta nota en la sexta al aire o en el segundo o tercer traste cuando fuera posible. La solución óptima era contener la música entre los "diecinueve puntos" (dos octavas y una quinta) de la sexta al aire al séptimo traste en la prima, o quizás hasta el décimo traste si resultaba más cómodo y de mayor fluidez musical. La cuestión de comodidad es importante ya que influye en la capacidad del tañedor de conseguir máxima musicalidad en su interpretación. Una pieza cómoda suele estar puesta en el instrumento para evitar posturas complicadas y movimientos excesivos de la mano izquierda, o digitaciones difíciles que fatiguen la mano innecesariamente. En términos generales, esta comodidad se consigue a través de una afinación que permita un buen número de cuerdas al aire, sobre todo en obras de polifonía densa. La vihuela en sol es la que favorecían los vihuelistas y, en general, las obras Cabezón no suelen descender mucho más bajo que la $\operatorname{sol}_{2}$ (Gamaut) de su sexta al aire, especialmente en su juego temático. En obras que emplean $f a_{1}$ o re $e_{1}$, el vihuelista puede elegir acomodar las obras como si la vihuela fuera afinada en $f a$ o re, o acomodarlas para una vihuela en $\mathrm{sol}$, transportando las notas graves una octava.

Para ejemplificar este proceso, consideremos el inicio de una de las versiones de Cabezón del himno Ave maris stella. ${ }^{32} \mathrm{Su}$ ámbito es de tres octavas de $r e_{2}$ a $r e_{5}$, mayor de lo que cabe en la vihuela. Dentro de sus 41 compases, hay un solo pasaje (compases 7 a 14) que utiliza el registro más agudo, desde $l a_{4}$ a $r e_{5}$, y solamente dos lugares donde se emplean las notas inferiores a $s o l_{2}: f a_{1}$ en el compás 33 , y $f a_{1}$ y $r e_{1}$ en la cláusula final de la obra. También se observa en el registro bajo que la $\mathrm{Sol}_{2}$ solamente aparece cuatro veces en toda la pieza. A base de estas observaciones, las afinaciones más propicias para tocar la pieza en la vihuela serán sol, la o $r e$. En teoría, la vihuela en re es la única afinación en la que caben todas las notas, el ámbito completo, pero con posibles dificultades en el registro más agudo en los compases 7 a 14 como hemos indicado. En cambio, las vihuelas en sol y la se prestan mejor para este registro superior, pero será necesario transportar a la octava las notas del bajo que hemos indicado. En el Ejemplo 1, presentamos el inicio de la obra: una transcripción en notación moderna seguida por las cifras originales, y nuestra adaptación en cifras para vihuelas en $l a$,

32 CABEZÓN, 1578: fol. 21v; CABEZÓN, 2010: vol. I, 164, no 33 . 
sol, y re. En cada una de las vihuelas se puede tocar toda la música original sin cambios ni omisiones. La versión en la es la que mejor cabe en el instrumento, es decir, tiene catorce cuerdas al aire, ninguna extensión grande para la mano izquierda, y ningún salto de posición. La adaptación en sol es parecida, incluso con más cuerdas al aire (16), pero con un salto para la mano izquierda en los compases 7 y 8 que requiere más destreza para conseguir la fluidez deseada. En cambio, la versión en re utiliza el registro extremo del instrumento, incluso el duodécimo traste que no se emplea en ninguna fuente original para vihuela. El resultado es incómodo, poco idiomático, y no conforme con la práctica de la época definida a raíz de las fuentes conservadas.

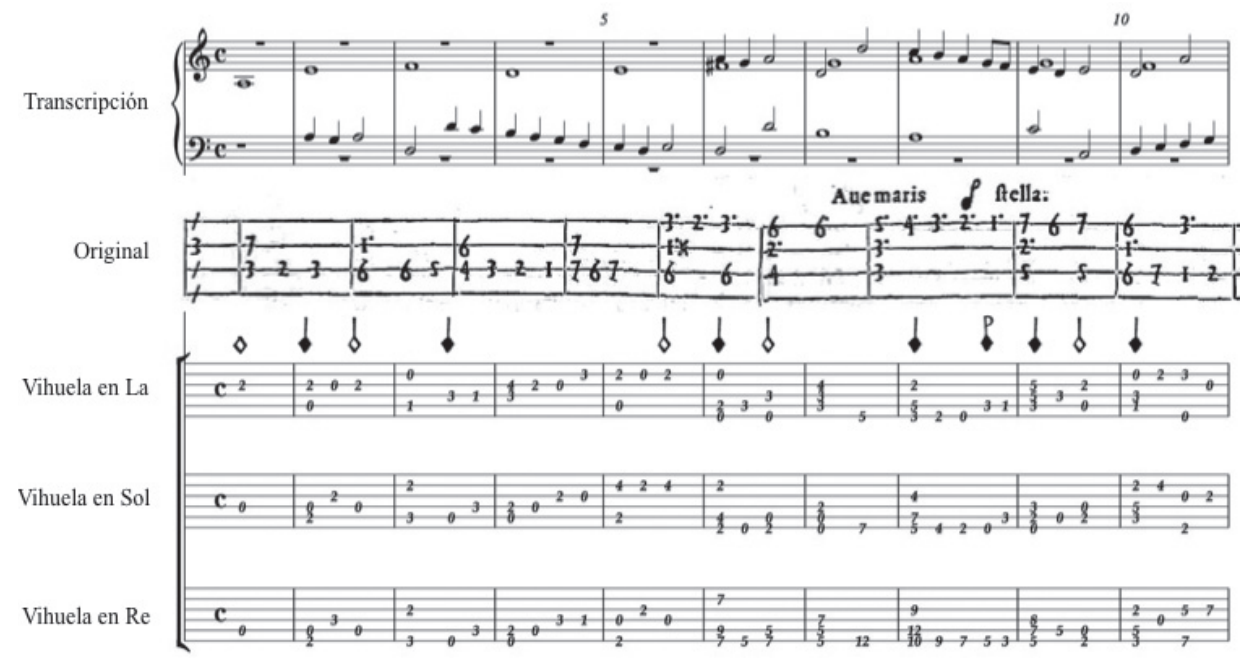

Ejemplo 1. Cabezón, Ave maris stella, Obras de música, n 34, compases 1-14.

El segundo pasaje a considerar es el final de la obra, compases 36 a 41 (Ejemplo 2), presentado en el mismo formato que el ejemplo anterior, pero con transcripciones en notación moderna de las cifras para vihuela y las modificaciones indicadas. Igual que al comienzo de la obra, es la versión para la vihuela en re que acomoda la música original sin alteraciones, mientras las otras dos afinaciones suponen ciertos ajustes. En ambas versiones, hay que suprimir la $r e_{1}$ y hay que transportar a la octava el bajo en el compás 39. También en la versión en la, hay que omitir la primera nota del tenor porque es imposible digitar el acorde en una vihue- la en la, dado el intervalo de una tercera entre el bajo y el tenor. Otros acordes, como el primero en el compás 36 de la versión para vihuela en la requieren modificación, debido en este caso a su difícil digitación. Un acorde parecido inhibe la fluidez del intérprete en el compás 38 de la versión para vihuela en sol, y el pasaje suena mejor si se omite la $m i$ en el tenor de este acorde. Esto permitiría que el acorde fuese digitado en la configuración V/0 - III/0 - II/2, infinitamente más fácil de tocar, pero quizás más difícil de leer directamente de la cifra original para tecla. 

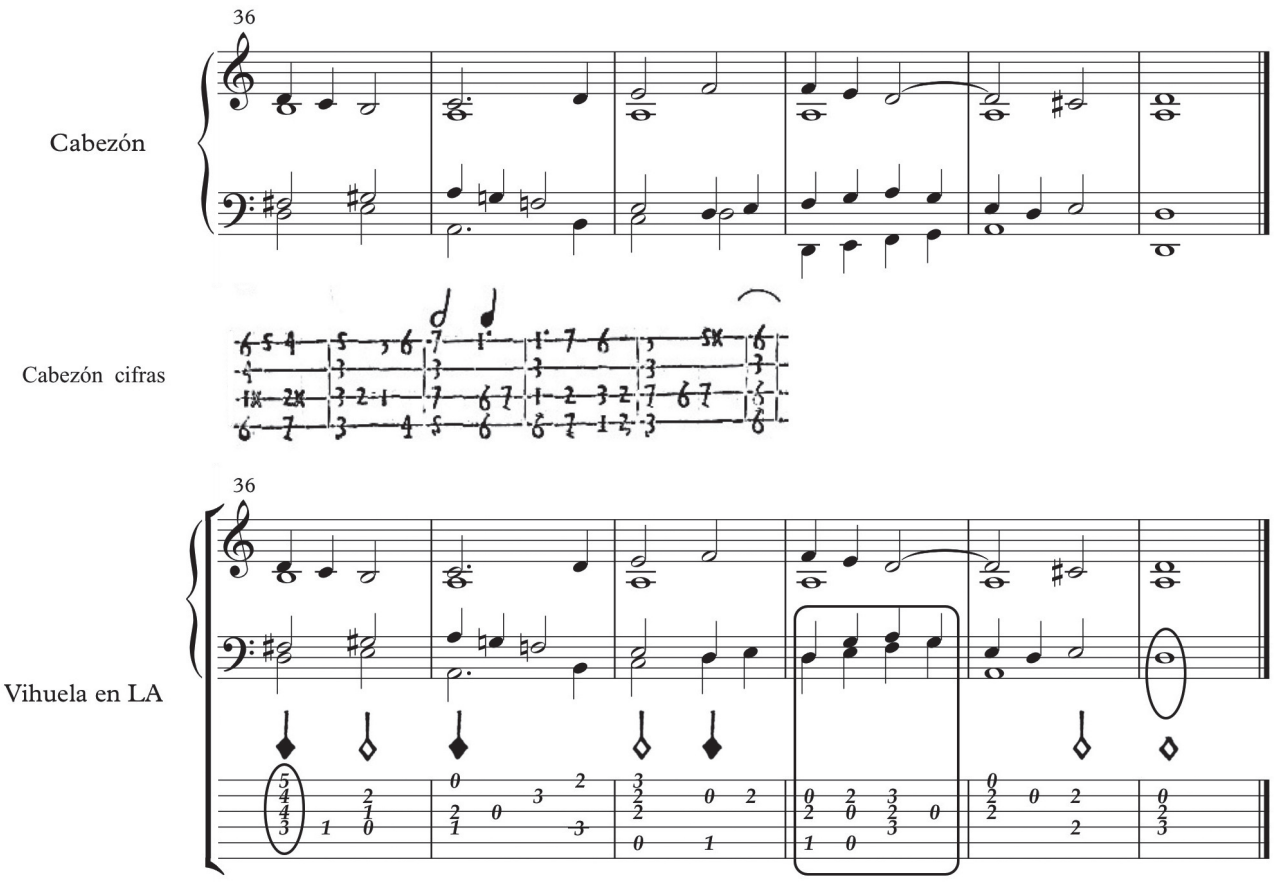

Vihuela en SOL

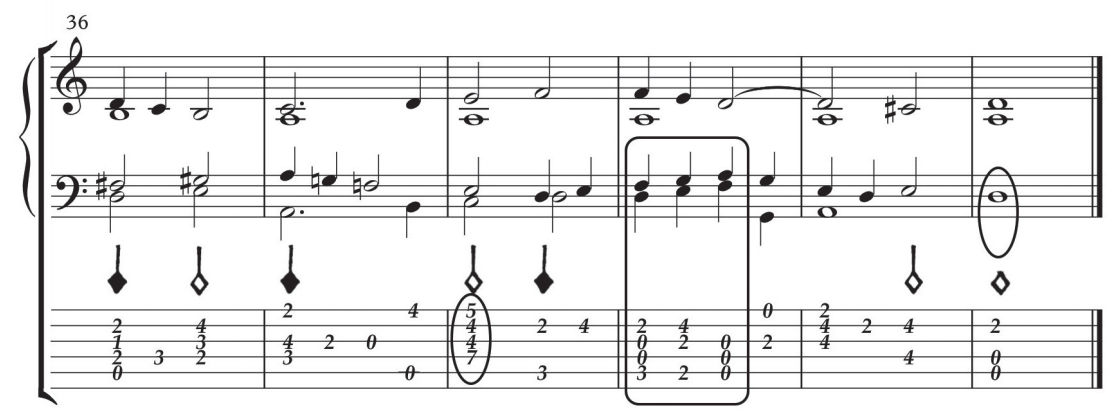

Vihuela en RE

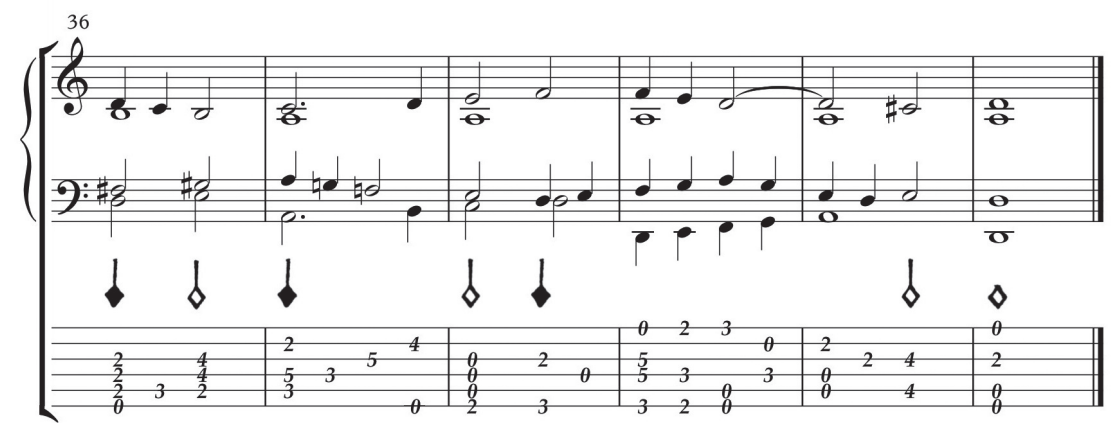

Ejemplo 2. Cabezón, Ave maris stella, Obras de música, nº 34, compases 36-41. 
Una de las razones principales que motivó a Juan Bermudo incluir grabados de los diapasones de sus siete vihuelas - afinaciones imaginarias de un mismo instrumento- fue para facilitar el trabajo del vihuelista que quisiera poner obras de polifonía vocal en cifra, para darle una herramienta fácil para ayudarle a poner música polifónica en la vihuela, pero por un proceso por escrito, escribiendo la polifonía en cifra para su instrumento. Obviamente opinaba que pocos vihuelistas tenían la habilidad de leer música polifónica directamente en la vihuela sin haberlo convertirlo en cifras previamente. El proceso de leer la cifra de Cabezón directamente en la vihuela no era fácil en sí por las razones que hemos explicado previamente, y sobre todo por la falta de conexión lógica e intuitiva entre la notación y el instrumento. Esta dificultad se multiplicaba en el caso de los que utilizaban las afinaciones múltiples con sus vihuelas imaginadas en $d o, f a$, sol, la o en la afinación que fuera. Se convierte en un ejercicio mental muy intenso, y con mayor dificultad en conseguir la inmediatez de respuesta para leer con fluidez. Si consideramos un breve ejemplo pedagógico en términos de las tres vihuelas que hemos contemplado, las en sol, la y re, la secuencia 12345 en la cifra de Cabezón que representa una escala ascendiente $f a$-sol-la-si-do se encontraría en el diapasón en tres configuraciones diferentes. Mantener la agilidad mental de no confundirse es algo que vencería a todos menos a los profesionales muy experimentados.
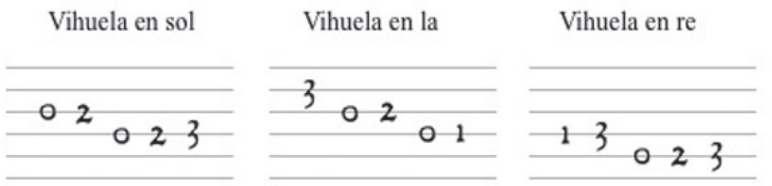

Ejemplo 3. Secuencia 12345 (fa-sol-la-si-do) de la cifra de Cabezón en diferentes vihuelas

\section{TIENTO DEL QUARTO TONO}

A través de un examen detallado de uno de los tientos de Cabezón, queremos dar un ejemplo del proceso por el cual se acomoda una de las Obras de música a la vihuela. DesignadoTiento VII en muchas de las grabaciones y ediciones del repertorio, el Tiento del quarto tono es una obra de 123 compases, compuesta de tres equilibradas secciones de aproximadamente cuarenta compases -1-39 // 40-83 // 84-123 - y un ejemplo representativo de la polifonía de su autor y de la arquitectura formal que tipifica el género de la fantasía-ricercare al que pertenece ${ }^{33}$. Es una de sus obras

33 CABEZÓN, 1578: fol. 59-60v; CABEZÓN, 2010: vol. II, 166-171, no 64. más difundidas en los últimos años, grabada por lo menos en versiones para órgano, clave y arpa.

Es ésta una obra principalmente imitativa, aparte de un pasaje en ritmo de gallarda que comprende la gran parte del la tercera sección, un buen ejemplo de la austeridad del contrapunto de Cabezón, infundida de disonancias audaces y animada por la sección final. El ámbito de la pieza es de tres octavas y un tono, de $\mathrm{re}_{2} \mathrm{a} \mathrm{mi}_{5}$, con su principales cadencias en los finalis y cofinalis del cuarto tono, mi y la. Similar al himno Ave maris stella que examinamos arriba y a pesar de sus tres octavas, la pieza se adapta cómodamente a una vihuela en la, según los criterios que hemos explicado. Es necesario omitir o transportar las nueve notas inferiores a $l a_{2}$, pero no es ningún problema ya que la mayoría de ellas ocurren en pasajes cadenciales, y nunca como parte del juego temático. En total, la adaptación a la vihuela requiere cambios a dieciséis de los 123 compases, un poco más del diez por ciento. Aparte de transportar los bajos demasiado profundos, la mayoría de los cambios se realizan para simplificar pasajes que contienen dos voces glosando a la vez de acuerdo con las explicaciones de Hernando de Cabezón. También hay algunos acordes que resultan más manejables si se quita una de sus notas, principalmente el tenor si es una tercera encima del bajo. Lo que se pierde en simplificar está compensado en mayor grado por lo que se gana en facilidad de ejecución y musicalidad.

Un ejemplo concreto del tipo de cambio sutil e imperceptible que haría un vihuelista para simplificar a favor de la fluidez musical se encuentra en los compases 13 y 14, acercando al primer pasaje cadencial (Ejemplo 4). Ante todo, para entender las decisiones que al vihuelista le tocaba, hay que recordar que la norma en la vihuela era la de repetir las notas largas al principio de cada compás para dar contundencia a la textura, y suprimir por consiguiente a las ligaduras en la pauta superior. La modificación obligatoria e inevitable que tiene que hacer el vihuelista es entonces omitir una de las notas del acorde inicial del compás 14 por ser imposible de digitar. Normalmente, la preferencia sería una omisión en una de las voces internas, y en este caso sería más lógico quitar el si en el tenor por ser la repetición del bajo y porque no juega un papel importante. El vihuelista también podría optar por omitir la misma nota del compás anterior para simplificar una digitación complicada y para mantener la claridad musical de un pasaje en el registro inferior de su instrumento. En el Ejemplo 4, presentamos la música de Cabezón sin modificaciones en la transcripción mensural del original, pero con el si suprimida en las cifras de vihuela en el compás 14, y con la cifra opcional en corchetes en compás 13. Estas modificaciones son del tipo que el vihuelista tiene que pensar con detenimiento ya que los acordes en ambos 
compases no corresponden al vocabulario de posturas típicas en la vihuela, sino acordes que hay que leer nota por nota en vez de reconocerlos en su conjunto. Además, en el caso de tocar directamente de las cifras originales, el vihuelista se tendría que enfrentar a la dificultad adicional en este pasaje del cruce de las voces contralto y tenor, una complicación debida a la naturaleza de la notación.

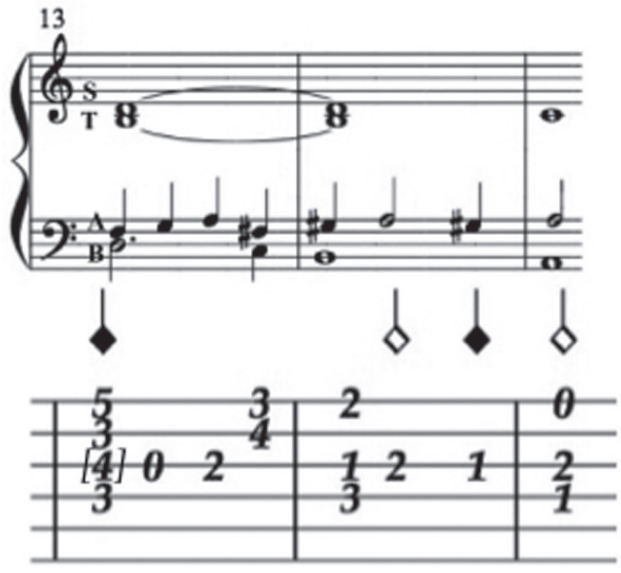

Ejemplo 4. Tiento del quarto tono, compases 13-15.

El pasaje cadencial que concluye el Tiento del quarto tono ejemplifica perfectamente los ajustes necesarios a las notas del bajo para que quepan en la vihuela en la. En el ejemplo 5, las cuatro notas afectadas se indican en gris y con un asterisco debajo. Las tres últimas se transportan a la octava superior, mientras la primera, sol $_{2}$ (compás 117) se omite por tener un $\mathrm{sol}_{3}$ en el mismo acorde. En el caso del $r e_{1}$ (compás 118), el transporte produce otro conflicto con el $f a_{3}$ que comparte la misma cuerda. La omisión de esta última nota es la solución más práctica en la vihuela, una vez más para evitar los problemas de digitación que resultan de tener terceras entre bajo y tenor. Del mismo modo, la omisión de la $f a_{3}$ en el tenor al principio del compás 115 también simplifica la postura de la mano y ayuda a conseguir una mejor adaptación.

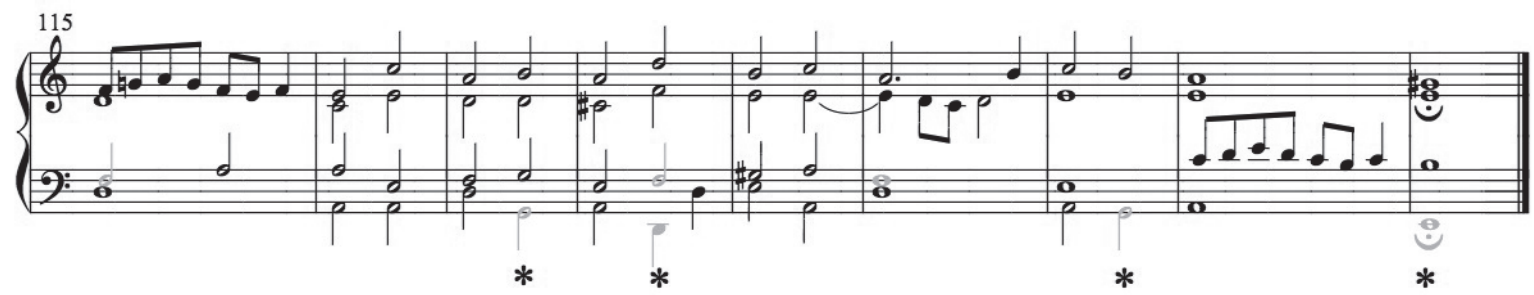

Ejemplo 5. Tiento del quarto tono, cc.115-123, con notas para transportar u omitir indicadas en gris

Para el vihuelista que tuviera su propio ejemplar de las Obras de música, señalar cambios de octava habría sido fácil ya que no requiere más que un cambio a la designación de octava en las cifras afectadas. En el ejemplo 6, se ven los cambios necesarios para las modificaciones en los com- pases 118 a 123 indicados en el ejemplo anterior, tachando la cifra 1 ( re $\left._{2}\right)$ en el tenor en el compás 118 , y modificando los dobles rasguillos en las cifras 6, 2 y 7 en compases 118 , 121 y 123 . 


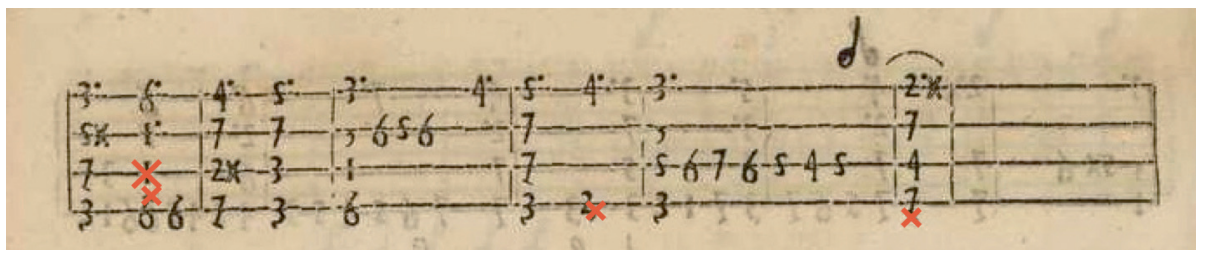

Ejemplo 6. Tiento del quarto tono, cc.118-123, con tachaduras indicadas

En el pasaje que concluye la primera sección del Tiento del quarto tono, en los compases 27 a 40 encontramos ejemplos del tipo de textura que Hernando de Cabezón aconseja simplificar para su interpretación en la vihuela debido a las glosas simultáneas en dos voces. En el Ejemplo 7, la música original se presenta en paralelo con algunas de las posibles adaptaciones para vihuela. En la versión 1, los compases en vacío (32-33) no requieren ninguna alteración. En los compases 27 y 34 a 37 hemos suprimido notas para evitar fusas simultáneas. En la primera de las dos versiones alternativas, hemos suprimido notas en ambas voces para mantener algo del juego contrapuntístico presentes en el original, mientras en la segunda versión alternativa hemos mantenido el soprano igual a la versión original y hemos suprimido la mayoría de las notas del contralto para dar una versión más espontánea y que quizás representara lo que haría un vihuelista en el acto. Aparte de la simplificación de las fusas, el bajo en los compases 29 a 31 contiene notas más bajas que $l a_{2}$, la sexta al aire de la vihuela en la. Hemos transportado estas notas a la octava junto con la voz del tenor que, por consiguiente, no podría mantener su altura original. En total, estos cambios son poco intrusos y están realizados con la intención de respetar el texto original al máximo. Son transformaciones mucho más discretas que las que hacía Venegas de Henestrosa, por ejemplo, en su adaptación de obras originalmente para laúd y vihuela de autores como Narváez, Mudarra y Francesco da Milano entre otros, y que en varias ocasiones son más bien composiciones nuevas ${ }^{34}$.
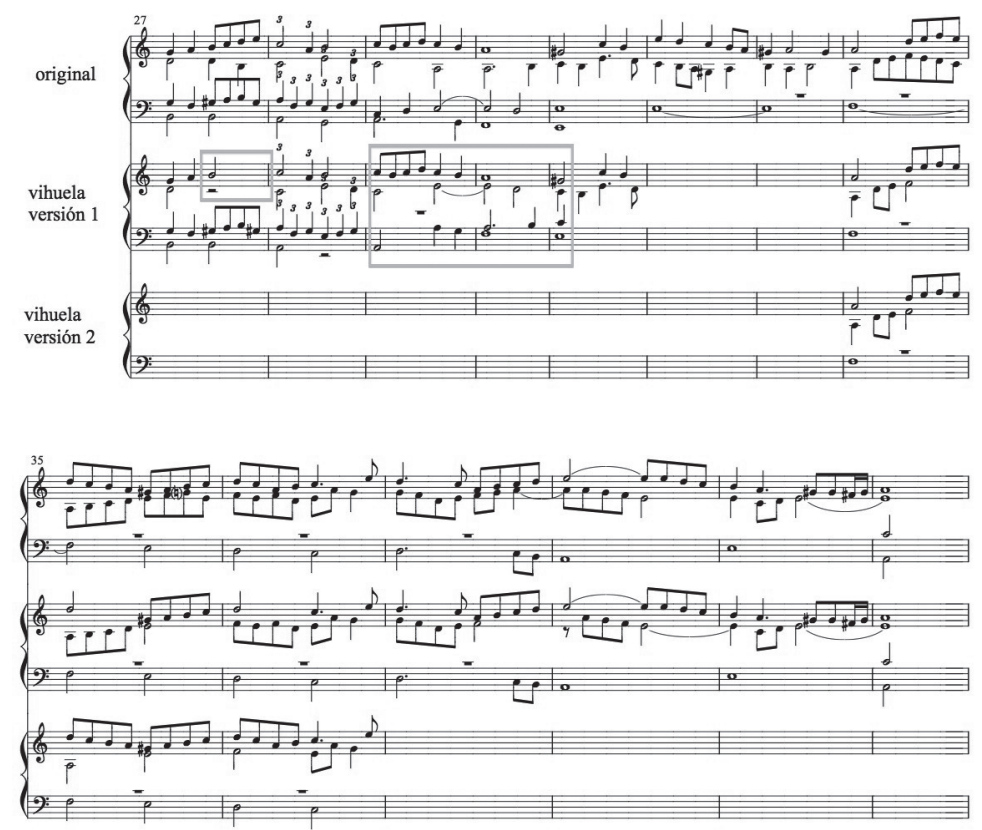

Ejemplo 7. Tiento del quarto tono, cc.127-140, transcripción literal y adaptaciones para vihuela. 


\section{REPERTORIO, ESTÉTICA Y SOCIEDAD}

Ahora cambiemos nuestro enfoque desde el contenido de las Obras de Cabezón hacia sus consumidores, aquellos vihuelistas que quizás adquirieron un ejemplar del libro atraídos por la reputación de su autor o debido a la promesa de su título de música "para tecla, arpa y vihuela". ¿Quiénes eran los tañedores y compradores del libro? ¿Para qué lo habrían utilizado, y en qué circunstancias? Estas simples preguntas son sorprendentemente difíciles de contestar dado lo poco que se sabe sobre dónde se tocaba la vihuela, la identidad de los propios vihuelistas, y los motivos que tenían para tañer.

En términos generales, sabemos que la vihuela estaba presente en la esfera cortesana, que no participaba en la música litúrgica, y que se escuchaba con frecuencia en las ciudades, sobre todo en las casas de profesionales cultos y, en menor grado, en las de algunos individuos de las capas artesanales y mercantiles. En el contexto cortesano, la vihuela se usaba para acompañar canciones y probablemente para música solista en manos de instrumentistas y cantantes profesionales. También la practicaban algunos de los nobles, tanto hombres como mujeres. En crónicas oficiales, memorias, cartas u otros relatos de ficción que recuerdan al mundo cortesano, no hay referencias a eventos comparables con lo que ahora entendemos por concierto. Lo más parecido son encuentros sociales sin designados protagonistas oficiales en los que intervenían artistas o cortesanos cantando a la vihuela o tocando, como era el caso en la corte valenciana que frecuentaba Luis Milán ${ }^{35}$. De los demás vihuelistas que conocemos que ocupaban puestos asalariados en la corte, particularmente Miguel de Fuenllana y Luis de Narváez, no tenemos ni una sola noticia de su participación en eventos de esta índole. Al contrario, la evidencia nos haría creer que eran músicos cuyo papel era más el de tocar en privado que en público, verdaderos músicos de cámara en el sentido literal de la palabra que formaban parte del equipo que acompañaban a los monarcas o príncipes, atendiéndoles en la intimidad de sus aposentos y habitaciones.

Para instrumentistas que no se dedicaban a la música de forma profesional, tañer la vihuela era un entretenimiento, una educación y, para otros, un tipo de meditación espiritual. En diversas anécdotas, vihuelistas de notable destreza se desafiaban para ver si tenían habilidad de improvisar en un instrumento destemplado, es decir, en una afinación desconocida y diferente a la habitual ${ }^{36}$. En tales situaciones, la

35 El estudio principal sobre este tema es GASSER, 1996.

36 BERMUDO, 1555: fol. 30, nombra a Miguel de Fuenllana y Luis de Guzmán entre los más destacados en tocar en vihuelas destempladas, añadiendo que Fuenllana lo vio "hacer a mi instancia excelentemente". vihuela era una herramienta para alentar la interacción social, algo para desafiar a la mente y a los reflejos, quizás en algunas ocasiones más para divertirse que para experimentar el profundo poder de la música. Al mismo tiempo, hay referencias a músicos que "hacían hablar las cuerdas", o sea, a tañedores que poseían la capacidad de despertar las más íntimas sensibilidades de sus oyentes, convirtiéndose en nuevos Orfeos o Apolos u otras figuras de la mitología. Son actuaciones que permiten que la vihuela, bien para el tañedor o el oyente, asuma una función terapéutica. Visto dentro del marco platónico, es la herramienta para afinar el cuerpo y el alma; y dentro de la filosofía cristiana, conduce a la realización espiritual a través de la reflexión. Subraya este valor moral el rey cuando emplea la frase "útil y provechoso" en las licencias de algunos de los libros de vihuela.

Dejando de lado la dimensión espiritual, la mayoría de los libros de vihuela tienen una función práctica y didáctica e incluyen materiales que permiten a sus lectores desarrollar su técnica instrumental y, quizás más importante, poder leer polifonía vocal en partitura, y así aprender contrapunto, armonía y técnicas de composición basadas en la polifonía vocal. Es una de las dimensiones que las cifras de Cabezón tienen en común con los libros de vihuela.

La producción de 1225 ejemplares de las Obras de música supone la expectativa de una amplia difusión ${ }^{37}$. No fue una publicación concebida para circular solamente entre profesionales, sino entre un público amplio que parece indicar, entre otras cosas, la existencia de un buen número de tañedores de alto nivel. Según la evidencia sacada de testamentos, inventarios y otros documentos civiles, la clientela de estos libros coincidía con los grupos que perfilamos en los párrafos anteriores, pero también incluía a religiosos que tocaban monacordios, vihuelas y arpas en sus horas de ocio, gente que apreciaba la música litúrgica contenida en el libro de Cabezón, aunque no les sirviera directamente en su labor vocacional.

El libro de las Obras de música de Cabezón está destinado claramente a los organistas por encima de cualquier otro grupo de instrumentistas. De acuerdo con su título original, es un compendio completo de la música que a un organista le haría falta, una diversidad de obras didácticas, música para la celebración litúrgica, más obras para uso recreativo y para tocar delante de un público de fieles dentro de los actos religiosos. Comienza con una colección sistemática de piezas didácticas en dos, tres y cuatro voces (24 obras),

37 Véase PÉREZ PASTOR, 1897. Este trabajo reproduce el contrato y documentos relacionados con la impresión de las Obras. Es una cifra comparable con los 1000 ejemplares de Orphenica Lyra de Miguel de Fuenllana y los 1500 ejemplares de El Parnasso de Esteban Daza y el Arte de tañer fantasía de Santa María. Véase GRIFFITHS, 2006. 
música para varias partes litúrgicas - fabordones, himnos, versos de Magnificat y Kyries (36 obras), tientos (12 obras), arreglos glosados de obras polifónicas (48 obras), y variaciones (10 obras). Gran parte de esta música habría sido de poco interés para los vihuelistas, y en su mayoría imposible de tocar. Solo una reducida proporción de las obras se acomoda fácilmente a la vihuela, empezando con las obras didácticas a dos y tres voces que, aparte de ayudar al tañedor a comprender cómo funciona el contrapunto, también sirven para adquirir facilidad en la lectura de sus cifras. Algunos de los tientos se adaptan a la vihuela sin grandes modificaciones, igual a las distintas diferencias debido, sobre todo, a la naturaleza idiomática de su composición y la destreza del tañedor. En cambio, los arreglos de obras polifónicas son demasiado complejos para adaptar a la vihuela, menos alguno que podría adaptarse con modificaciones sustanciales. La mayoría de las composiciones litúrgicas tampoco se adaptan de forma convincente dado la dificultad inherente de sostener los cantus firmus en la vihuela. Es únicamente dentro de la obra de Luis de Narváez donde encontramos diferencias sobre himnos compuestos de forma análoga a las versiones de Cabezón. Quizás no sea completamente una coincidencia, Narváez y Antonio de Cabezón se movían en los mismos círculos dentro de la corte durante las décadas de los 30 y 40 , y por lo tanto eran probablemente compañeros en el séquito que acompañó a Felipe II en su viaje a Alemania, y a los Países Bajos en 1548 y 1549.

En el intento de evaluar la recepción de las Obras de música entre vihuelistas, hay que recordar que Hernando de Cabezón tardó doce años desde la muerte de su padre hasta publicar su música en 1578, dos años después del último libro para vihuela, El Parnasso de Esteban Daza, editado en Valladolid en 1576 en un momento de inminentes cambios en el gusto musical en España. De los documentos sacados a la luz por Pérez Pastor vemos claramente que las Obras de música fue un fracaso comercial, quizás por cambios de gusto, si no por haber diminuido el prestigio de su autor en el periodo de tiempo que había transcurrido desde su muerte, o por no tener acceso a las vías adecuadas de distribución. Por el conjunto de razones que fuera, lo que sabemos es que Hernando de Cabezón vendió una gran parte de la tirada a un librero poco tiempo después de su edición por un precio poco favorable. La evidencia tiende a afirmar que el librero tampoco tuvo mucho más éxito que el mismo autor. En mayo de 1581, solamente tres años después de su publicación, Hernando de Cabezón todavía tenía más de ochocientos ejemplares en su poder, lo cual significa que en ese tiempo no había conseguido deshacerse - vendiendo u obsequiando - de más de 450 ejemplares, o incluso menos. En cualquier caso, en esta fecha vendió ochocientos ejemplares al librero Blas de Robles por un precio de ocho mil reales, diez reales por tomo ${ }^{38}$. Aunque fuese solamente el sesenta por cien del precio de venta establecido por el Real Consejo de un ducado y medio, habría permitido a Hernando liquidar cualquier deuda ocasionada por el ejercicio editorial que le costó un total de 5110 reales $^{39}$. Al mismo tiempo, el acuerdo habría permitido a Robles sacar un beneficio razonable. Robles acordó pagarle a Cabezón en cuotas anuales de mil reales durante ocho años. Esta cifra representaría una posible venta de cien ejemplares al año, o menos si Robles los vendiera por su precio oficial. Por lo visto, Robles no logró vender lo suficiente para cumplir con el acuerdo y, habiendo recibido solamente dos mil reales después de cinco años, Cabezón inició un pleito en 1586 para recuperar del librero lo que le debía. Nunca se puede descartar la posibilidad de jugadas deshonradas en este tipo de negocio, pero si nos basamos puramente en las cifras, es posible que Robles no consiguiera vender más de dos cientos ejemplares de las Obras de música en los cinco años de 1581 a 1586.

\section{INTERCAMBIO LIBRE Y RECÍPROCO}

Para entender la publicación de las Obras de música de Cabezón en el desarrollo de la música instrumental en España, es necesario examinarlo en el contexto de los otros libros anteriores destinados a los mismos instrumentos: el Libro de cifra nueva de Luis Venegas de Henestrosa (1557) que también es para "tecla, arpa y vihuela", y el Arte de tañer fantasía de Tomás de Santa María (1565) que se declara "para tecla como para vihuela, y todo instrumento en que se pudiere tañer". Ambos libros tienen una relación directa con la colección póstuma de Cabezón, aquel por ser tan claramente el modelo que sirvió a Hernando de Cabezón y éste por la declaración que lleva en su portada de haber sido "examinado, y aprobado por el eminente músico de su Majestad Antonio de Cabezón, y por Juan de Cabezón su hermano." Sería de sorprender si Venegas tampoco conociera personalmente a Antonio de Cabezón debido a las treinta y seis de sus obras que contiene, un número suficientemente grande para suponer que las publicara con su autorización sobre todo siendo un autor cuya música evidentemente no circulaba libremente.

38 PÉREZ PASTOR, 1897: 370. 39 GRIFFITHS, 2006: 204. 


\section{SANTA MARÍA, EL ARTE DE TAÑER FANTASÍA}

El Libro llamado Arte de tañer fantasia, assi para Tecla, como para Vihuela de Tomás de Santa María salió de la imprenta de Francisco Fernández de Córdoba en 1565, casi al final de la vida del protagonista Antonio de Cabezón y fue producto de

diez y seys años continuos de lo mejor de mi vida, passando innumerables y increybles trabajos de día y de noche, inuentando cada dia cosas, y deshaziendo otras, y tornandolas a hazer hasta ponerlas en perfection, y en reglas vniuersales, y comunicando cosas con personas diestras, y entendidas en esta facultad, especialmente con el eminente musico de su Magestad Antonio de cabeçon ${ }^{40}$.

En términos generales se puede describir el libro de Santa María como un tratado para instrumentos de tecla que, igual al libro de Cabezón y según reza su portada, también era apto para "todo instrumento en que se pudiere tañer a tres, y a quatro, y a más" voces ${ }^{41}$. Es, sobre todo, un libro para instrumentos de tecla, y las referencias a la vihuela y otros instrumentos polifónicos son escasas. Dividido en dos libros, el primero trata de material preliminar, bien sea fundamentos de música o técnica instrumental, y el segundo se dedica al arte de la improvisación polifónica e imitativa. El Libro segundo trata temas genéricos que sirven igualmente para todos los instrumentos, con unos treinta capítulos dedicados a la armonía y una teoría de consonancias y progresiones, seguidos por veintitrés capítulos sobre contrapunto imitativo. En cambio, el Libro primero contiene capítulos sobre notación (1 a 6), la teoría musical aplicada (7 a 12), digitación en el teclado (13 a 18), seguido por cinco capítulos sobre varios aspectos de la interpretación (19 a 23), y tres sobre los tonos (24 a 26). Dentro de este Libro primero, hay solamente una referencia específica a la vihuela (cap. 20), aunque los capítulos dedicados al arte de glosar y a la interpretación rítmica desigual son de aplicación universal. En el capítulo 20, Santa María se dedica a la vihuela al lado de las instrucciones que ofrece para el monacordio. Se refiere a temas como los metros y el compás, y a las dificultades asociadas a la lectura de polifonía desde fuentes vocales. Sigue con sus instrucciones sobre la localización de las notas de la música mensural en el teclado y la vihuela. El grabado que

40 SANTA MARÍA, 1557: fols. *2v-*3v.

41 No menciona específicamente al arpa. La portada del libro también consta que el libro fue "examinado y aprouado por el eminente músico de su Magestad Antonio de Cabeçón, y por Iuan de Cabeçon su hermano". incluye en el fol. 56v es de una vihuela común en sol, con un hexagrama normal de seis órdenes formando el diapasón con los nombres de las notas, Gamaut, Are, etc, al lado de las cifras. Su texto comenta sobre los trastes, la digitación de la mano izquierda, la diferencia entre cuerdas al aire y las demás notas, y una breve explicación de la notación en cifras para vihuela. No hay ningún intento de relacionar la vihuela con la cifra nueva inventada por Venegas unos años antes.

\section{VENEGAS DE HENESTROSA, LIBRO DE CIFRA NUEVA}

Del contrato entre Hernando de Cabezón y Francisco Sánchez para la impresión de las Obras de música, aprendemos cómo y hasta qué punto el Libro de cifra nueva de Venegas de Henestrosa le sirvió de modelo. En el contrato se establece que los tipos para la cifra tienen que ser nuevos, y especifica "que los números que ha de llevar la dicha impresión en las reglas los ha de hacer fundir el dicho Francisco Sánchez más corpulentos que los que están en el dicho libro de Hinestrossa, de manera que queden más gruesos y cubiertos de tinta que los del dicho libro, y se pueden leer y entender con más claridad" ${ }^{42}$. Al mismo tiempo, clarifica que el estilo de la tipografía debe basarse en la de Venegas, y requirió que Sánchez firmara su ejemplar del Libro de cifra nueva para señalar que se había familiarizado con el libro. Así, el contrato aclara "que los números y letra de los dichos libros han de ser del tamaño, suerte y forma de la en que está impreso un libro de Hinestrossa de tecla y vihuela impreso en Alcalá, que queda en poder del dicho Hernando de Cabezón

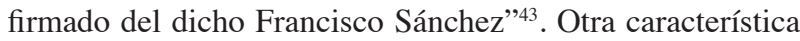
del Libro de cifra nueva que Hernando de Cabezón quería copiar eran los grabados de los instrumentos que Venegas incluye en folio 9 de su texto preliminar. En la cuarta cláusula del contrato, la única del acuerdo que quedó sin cumplir, Cabezón especifica "que dentro del dicho libro... ha de poner dos estampas, una de vihuela y otra de arpa, las cuales [el impresor] ha de buscar o hacer cortar..." Éstos son los grabados que indican la posición de las cifras en las cuerdas del arpa y los trastes de la vihuela.

Un examen minucioso revela otros detalles del libro de Cabezón que posiblemente se basan en el Libro de cifra nue$v a$. En particular, hay una relación estrecha entre el orden de obras en ambos libros, aunque también hay diferencias notables que muestran una cierta correspondencia con el plan que

42 Ibid.

43 PÉREZ PASTOR, 1897: 366. 
ofrece Venegas para su proyectada serie de siete volúmenes de la cual el Libro de cifra nueva iba a ser el primero. En el "Prólogo y argumento deste libro" (fol. 3), Venegas proyecta "siete libros en dos cuerpos" añadiendo que "lo que se contiene en el primero (que es el que sale agora a luz) en su tabla se verá" y que los libros restantes "aunque están hechos, no salarán, hasta ver el prouecho que haze el primero", una promesa muy parecida a la que hizo Luis de Narváez casi veinte años antes ${ }^{44}$. Venegas sigue, añadiendo que:

Van los que quedan en este orden. El segundo lleua entradas de versos, y himnos, y tientos. El tercero contiene hymnos de maytines, y ensaladas, y villancicos, y chansonetas. El quarto missas. El quinto es de obras a siete y a ocho y a diez, y a doze, y a catorze de Criquillon y Phinot, y de otros graues componedores. El sesto es de canciones, a quatro, ya cinco, ya seis. El séptimo, es de differentes obras glosadas y cosas para discantar.
Este orden recuerda al orden de la música en las Obras de música de Cabezón con la excepción de los tientos que ubica entre las misas (libro 4) y las versiones en cifra de composiciones polifónicas (libros 5 y 6). Si creemos que las palabras del Rey en la licencia de las Obras de música procede de una carta de suplicación remitido por Hernando de Cabezón, el autor declara de haber "hecho y ordenado un libro intitulado Compendio de música" y, en la portada, "recopiladas y puestas en cifra por Hernando de Cabezón", parece probable que el orden de las piezas en el libro es obra suya, y que el paralelismo con el libro de Venegas no es ni coincidencia ni está de acuerdo con ninguna convención establecida. En la Tabla 1 indicamos en la columna central el orden de los géneros en las Obras de música comparado con las mismas secuencias en el Libro de cifra nueva a la izquierda, y la serie de publicaciones proyectada por Venegas a la derecha.

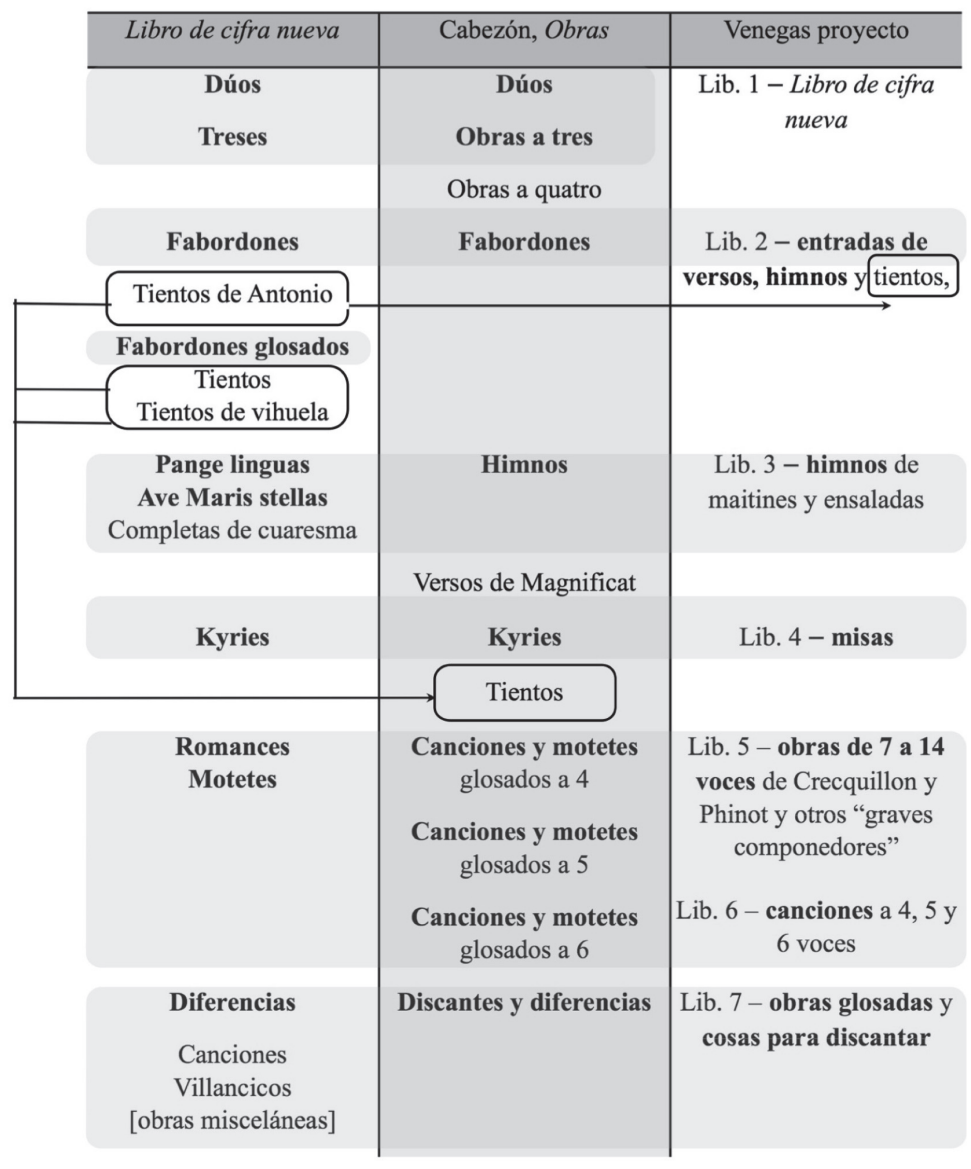

Tabla 1: Cabezón y Venegas de Henestrosa, orden musical de sus libros 
Dada la dependencia de Hernando de Cabezón en el Libro de cifra nueva en cuestiones de tipografía y en el orden de las obras, y en todo lo relacionado con el aspecto físico y externo del libro, hay otra posibilidad igualmente sostenible que su título y la decisión de imprimir la música de su padre bajo el lema de música "para tecla, órgano y vihuela" originara como resultado directo del libro de Venegas. Aunque ambos autores claramente compartían una preferencia marcada por el órgano, fue Venegas quien reconoció haber compuesto su libro "recogiendo muchas obras de diuersos autores, assí de tecla como de vihuela: y componedores" ${ }^{45}$.

Encontramos dos explicaciones del por qué. La primera se basa en que Venegas creía que el sistema de cifras que había inventado, realmente podría convertirse en una notación universal que serviría a todas los instrumentos polifónicos, una notación que dentro de poco podría suplantar a los demás sistemas y lograr aceptación por parte de los arpistas y vihuelistas al igual a los tañedores de instrumentos de tecla. No declara este objetivo directamente, pero es más que evidente teniendo en cuenta las instrucciones específicas y detalladas que ofrece a los tañedores de todos los instrumentos, que veía a su propuesta notacional con un espíritu noble y ecuménico, quizás pensando también en términos mercantiles y de una clientela aumentada.

Venegas sabía, por lo visto, de la escasez de música para instrumentos de tecla en ediciones impresas, sobre todo en comparación con la gran cantidad de ediciones para laúd y vihuela aparecidos desde 1536 hasta la fecha de su propia publicación. En el epígrafe de su prólogo titulado "Para pasar la cifra antigua de la vihuela a ésta", el autor llama la atención a la cantidad, calidad y variedad de música ya publicada para vihuela, empleando este último término en su acepción más amplia, refiriéndose no solamente a la vihuela propiamente dicha sino también al laúd, instrumento que en otra parte de su prólogo llama "vihuela de Flandes". Creía que su "cifra nueva" ofrecería a los organistas y tañedores de monacordios la posibilidad de ampliar su repertorio a través de transcripciones de música originalmente en cifra de laúd y vihuela:

Atentos a los muchos y eminentes músicos que ay de vihuela, assí estranjeros como españoles de differentes ayres y maneras de tañer, me pareció que sería bien abrir a los músicos de tecla y harpa la puerta de toda la música de vihuela, que ay impresa de cifra en esta declaración: la qual querría que fuesse a todos tan agradable, como a mí me ha sido trabajosa; si a alguno le pareciere escura con la vihuela que se pone abaxo le será clara ${ }^{46}$.

45 VENEGAS DE HENESTROSA, 1557: fol. 3. 46 VENEGAS DE HENESTROSA, 1557: fol. 3v.
Sus instrucciones realmente ofrecen un método de transcripción fácil que perfectamente podría "abrir la puerta" para cualquier tañedor de instrumentos de tecla a un repertorio extenso y de muy buena calidad. Hasta la publicación del Libro de cifra nueva en 1557 ya se habían publicado unos ochenta y cinco tomos para instrumentos de cuerda pulsada a lo largo del siglo, mientras que el número correspondiente de ediciones para tecla no superaba la veintena ${ }^{47}$.

En el mismo periodo y en todo el s. XVI no se conoce ninguna edición dedicada exclusivamente al arpa y, de hecho, la única obra que se conserva primariamente para el instrumento en todo el siglo es el breve tiento que incluye Mudarra al final de su libro de vihuela más que nada para mostrar la nueva forma de cifra que había inventado para el instrumento ${ }^{48}$. Así es que, entre las 138 obras en el libro de Venegas y las 129 de Cabezón, no hay ninguna obra escrita originalmente para arpa, pero en el Libro de cifra nueva hay dieciocho fantasías y dos fabordones "de vihuela", que son adaptaciones de obras para vihuela y laúd de Francesco da Milano, Luis de Narváez, Alonso de Mudarra, y Enríquez de Valderrábano ${ }^{49}$. Como ha mostrado Ward, Venegas no simplemente transcribe las obras de una notación a otra, sino las modifica de diferentes maneras, añadiendo glosas, fusionando partes de piezas diferentes en una sola, intercalando nuevos pasajes de su propia composición, o quitando compases de las obras sin cuidarse de la integridad de las obras originales ${ }^{50}$. Son modificaciones realizadas por un organista, y dificultan si no imposibilitan su interpretación con la vihuela. Frecuentemente exceden el ámbito de la vihuela común de seis órdenes, o incluyen acordes y progresiones imposibles de tocar sin omitir notas o pasajes enteros. A pesar de sus intenciones altruistas hacia todos los instrumentos polifónicos, estos arreglos afirman que Venegas, al igual que Cabezón, no era más que un organista.

La última cuestión que merece nuestra atención es si el libro de las Obras de música de Antonio de Cabezón realmente está pensado principalmente o exclusivamente para instrumentos de tecla, o si su confección deja margen real para la interpretación de las obras en arpa y vihuela. El veredicto cae plenamente a favor de los instrumentos de tecla: se

47 Estas cifras se basan en las ediciones inventariadas en BROWN, 1967, e incluyen las ediciones para laúd, vihuela y guitarra, pero excluyen las reimpresiones y las antologías de canciones con acompañamiento. Las ediciones para tecla incluyen música en todos los formatos corrientes.

48 "Tiento para arpa u órgano", MUDARRA, 1546: lib. 3, fol. 61. Edición moderna en MUDARRA, 1949: 135.

49 Para las concordancias, véase BROWN, 1967: 175-76.

50 Estos procedimientos están analizados con pormenor en WARD, 1952. 
trata de obras de un organista, concebidas para tecla, escritas en una notación basada en un teclado, y repletas de texturas que no se adaptan a los demás instrumentos sin modificaciones y simplificaciones. No podía estar mejor expresado que en los párrafos finales del largo y denso prólogo del libro. Dentro de su intensa defensa de la música en la que invoca una amplia gama de filosofía antigua y moderna, teología y leyendas clásicas que resaltan la profundidad de sus conocimientos y creencias musicales, Hernando de Cabezón se dedica a la alabanza del órgano, instrumento cuyas "ventajas [...] a los demás instrumentos [...] son manifiestas y claras," algo que "cada uno fácilmente entenderá, aunque no sepa música... Y como dijimos también que era la música una arte dedicada a Dios y al culto divino." Creía rotundamente y apasionadamente en "la majestad y señorío deste instrumento." ${ }^{51}$

En un artículo reciente, Francisco Roa nos recuerda los nombres de algunos músicos renombrados del siglo XVI expertos en más de un solo instrumento, principalmente tecla y arpa, o tecla y vihuela, y de unas referencias a ocasiones en que se escuchaba a conjuntos instrumentales que incluían algunos o veces todos los instrumentos a los cuales se dedica el libro de Cabezón ${ }^{52}$. Son detalles anecdóticos que sirven para recordarnos lo poco que sabemos y la insuficiencia de información de que disponemos en cuanto a la práctica instrumental en España. Aunque sean anécdotas veraces, no proporcionan detalles de la música que tocan, y no hay por qué creer que sería música de Cabezón. Más bien tocarían obras propias, quizás concebidas directamente en los diferentes instrumentos, en vez de piezas adaptadas y transferidas de un instrumento a otro. Al contrario y tomando todo en su conjunto, parece poco probable que la música de Antonio de Cabezón resonara con frecuencia en las vihuelas del s. XVI, sobre todo las obras editadas en 1578, pero también las que se publicaron en libro de Venegas de Henestrosa de 1557. A pesar de las aspiraciones universalistas de Venegas y de la adopción de su notación para el arpa en España hasta el siglo XVIII, su cifra no se presta de forma fácil e intuitiva a la vihuela. Aplicada a la vihuela, contradice la razón fundamental que subyace la existencia de las notaciones idiomáticas en letras o cifras, la de simplificar la escritura musical y poner música difícil al alcance de instrumentistas sin avanzados conocimientos musicales. Para el

51 CABEZÓN, 1578: fols. v-vv .

52 Véase ROA ALONSO, 2011. Este artículo, recibido durante los últimos momentos de la redacción del presente trabajo también ofrece información y perspectivas muy interesantes en cuanto a la producción de música instrumental en España durante la época de Cabezón, y sobre la imprenta musical. vihuelista, la cifra nueva de Venegas y Cabezón no simplifica sino complica su acceso, y le obliga a invertir un esfuerzo considerable para dominar una notación que va en contra de la naturaleza de su instrumento. Si añadimos a esto las complicaciones adicionales que surgen de los transportes, modificaciones y simplificaciones que requiere la música de Cabezón en la vihuela, se entiende por qué los vihuelistas y guitarristas perseveraron con su propia notación idiomática durante dos siglos más. A pesar de las declaraciones de Hernando de Cabezón en cuanto a la inmortalidad de la música de su padre, la realidad es que la música de Antonio de Cabezón, igual que la de Miguel de Fuenllana o cualquier otro vihuelista que profesaba un estilo musical severamente polifónico, fue progresivamente eclipsada en las últimas décadas del siglo XVI por una música ligera que, rasgueada en las cuerdas de las guitarras, correspondía a los impulsos creativos de una nueva época.

No se ha descubierto rastro alguno de si durante este periodo los vihuelistas conservadores aficionados a la polifonía imitativa ampliaron su repertorio con música de Antonio de Cabezón a través de sus obras en el Libro de cifra nueva de Venegas de Henestrosa o las Obras de música de Hernando de Cabezón. Hasta el momento no ha salido a la luz ninguna referencia a Cabezón en torno a la vihuela, no se ha descubierto ningún ejemplar de los libros en cuestión con indicaciones de haber sido utilizados en la vihuela, y no se ha encontrado ningún inventario de bienes que incluya a una vihuela junto con un ejemplar de un libro en cifras para tecla, arpa y vihuela.

\section{BIBLIOGRAFÍA}

ANGLÉS, Higinio, La música en la corte de Carlos V con la transcripción del "Libro de cifra nueva para tecla, harpa y vihuela" (Alcalá de Henares, 1557) compilado por Luys Venegas de Henestrosa, 2 vols, Monumentos de la Música Española 2 y 3, Barcelona, Consejo Superior de Investigaciones Científicas, 1944, reimp. 1965.

BAENA, Gonzalo de, Arte de tanger pera o instrumento de tecla, Lisboa, Germão Galharde, 1540.

BERMUDO Juan, Comiença el libro llamado declaracion de instrumentos musicales, Ossuna, Juan de León, 1555.

BROWN, Howard M., Instrumental Music Printed Before 1600: A Bibliography, Cambridge (Mass.), Harvard University Press, 1967.

CABEZÓN, Antonio de, Obras de Musica para tecla, arpa y vihuela, de Antonio de Cabeçón, Músico de la cámara 
y capilla del Rey Don Philippe nuestro Señor. Recopiladas y puestas en cifra por Hernando de Cabeçón su hijo. Ansí mesmo Músico de cámara y capilla de su Magestad, Madrid, Francisco Sánchez, 1578.

CABEZÓN, Antonio de, Obras de música para tecla, harpa y vihuela... Nueva edición crítica completa, edición de Javier Artigas Piña, Gustabo Delgado Parra, Antonio Ezquerra Esteban, Luis Antonio González Marín, José Luis González Uriol, José Vicente González Valle, 4 vols. Zaragoza, Institución Fernando el Católico, 2010.

DODERER, Gerhard, "Os manuscritos MM 48 e MM 242 da Biblioteca da Universidade de Coimbra e a presença de organistas ibéricos", Revista de Musicología, 34 (Madrid, 2011): 43-62.

DOÑAS, Antonio, "La tradición literaria e iconográfica del proverbio medieval 'como el asno a la vihuela", Hispanica Lyra, 11 (Madrid, 2010): 20-23.

GASSER, Luis, Luis Milán on Sixteenth-Century Performance Practice, Bloomington y Indianapolis, Indiana University Press, 1996.

GRIFFITHS, John, "Printing the Art of Orpheus: Vihuela Tablatures in Sixteenth-Century Spain", Early Music Printing and Publishing in the Iberian World, Iain Fenlon y Tess Knighton (eds), Kassel, Edition Reichenberger, 2006: 181-214.

GRIFFITHS, John, "La producción de libros de cifra musical en España durante el siglo XVI", Hispanica Lyra, 11 (2010): 10-27.

KASTNER, Santiago, "Los manuscritos nos 48 y 242 de la Biblioteca General de la Universidad de Coimbra," Anuario Musical, 5 (Barcelona, 1950): 78-96.

KNIGHTON, Tess, "A newly discovered keyboard source (Gonzalo de Baena's Arte nouamente inuentada pera aprender a tanger, Lisboa 1540): a preliminary report", Plainsong and Medieval Music, 5 (Cambridge, 1996): 81-112.

MANCING, Howard, The Cervantes Encyclopedia, Westwood CT, Greenwood Press, 2004.

MUDARRA Alonso, Tres libros de música en cifras para vihuela, Sevilla, Juan de León, 1546.

MUDARRA Alonso, Tres libros de música en cifras para vihuela, ed. Emilio Pujol, Monumentos de la Música
Española 7, Barcelona, Consejo Superior de Investigaciones Científicas, 1949.

OVIEDO, Luis de, Methodo de collection y reposición de las medicinas simples, Madrid, Alonso Gómez, 1581.

OWENS, Jessie Ann, Composers at Work: The Craft of Musical Composition 1450-1600, New York, Oxford University Press, 1997.

PÉREZ PASTOR, Cristóbal, "Escrituras de concierto para imprimir libros." Revista de Archivos, Bibliotecas y Museos 3a época, 1 (Madrid, 1897): 363-71.

RUIZ JIMÉNEZ, Juan, "Insights into Luis de Narváez and music publishing in 16th-century Spain", Journal of the Lute Society of America, 26 (Massachusetts, 1993), $1-12$.

ROA ALONSO, Francisco Javier, “Tecla, arpa y vihuela: aspectos de la cultura material en la época de Cabezón", Revista de Musicología, 34 (Madrid, 2011): 109-132.

SANTA MARÍA, Tomás de, Libro llamado arte de tañer fantasia. Valladolid, Francisco Fernández de Córdoba, 1565.

SANTA MARÍA, Tomás de, Libro llamado arte de tañer fantasia, reimp. y edición de Luis Antonio González Marín, Monumentos de la Música Española 76, Barcelona, Consejo Superior de Investigaciones Científicas, 2007. SPINACINO, Francesco, Intabulatura de Lauto, Libro primo, Venecia, Petrucci, 1507.

SIMÓN DÍAZ, José, Bibliografía de la literatura hispánica, Madrid, Instituto "Miguel de Cervantes" de Filología Hispánica, 1950-1993.

VALDERRÁBANO, Enríquez de, Libro de musica de vihuela intitulado Silva de sirenas, Valladolid, Francisco Fernández de Córdoba, 1547.

VALENTE, Antonio, Intavolatura de Cimbalo (Naples, 1576), ed. Charles Jacobs, Londres, Oxford University Press, 1973.

VENEGAS DE HENESTROSA, Luys, Libro de Cifra Nueva para Tecla, Harpa, y Vihuela en el qual se enseña breuemente cantar canto llano, y canto de organo, $y$ algunos auisos para contrapunto. Alcalá de Henares, Joan de Brocar, 1557.

WARD, John, "The Editorial Methods of Venegas de Henestrosa," Musica Disciplina, 6 (s.1., 1952):105-13.

Recibido: 19.10 .2012

Aceptado: 19.10.2012 